\title{
Efficiency analysis of emergency departments in metropolitan areas
}

\author{
Can Akkan $^{\mathrm{a}, *}$, Melis Almula Karadayi ${ }^{\mathrm{b}}$, Yeliz Ekinci ${ }^{\mathrm{c}}$, Füsun Ülengin ${ }^{\mathrm{a}}$, Nimet Uray ${ }^{\mathrm{d}}$, \\ Elif Karaosmanoğlu ${ }^{\mathrm{e}}$
}

a School of Management, Sabanci University, Tuzla, Istanbul, 34945, Turkey

${ }^{\mathrm{b}}$ Department of Industrial Engineering, Istanbul Medipol University, Beykoz, Istanbul, 34810, Turkey

${ }^{\mathrm{c}}$ Department of Business Administration, Istanbul Bilgi University, Eyüp, Istanbul, 34060, Turkey

${ }^{\mathrm{d}}$ Department of Business Administration, Kadir Has University, Cibali, Istanbul, 34083, Turkey

${ }^{\mathrm{e}}$ Department of Management Engineering, Istanbul Technical University, Macka, Istanbul, 34367, Turkey

\section{A R T I C L E I N F O}

\section{Keywords:}

Efficiency analysis

Data envelopment analysis

Emergency departments

Turkey

\begin{abstract}
A B S T R A C T
The demand in the healthcare industry is increasing exponentially due to aging population of the world and this is leading to a rapid increase in the cost of healthcare. The emergency departments of the hospitals are the frontline of health care systems and play an additional critical role in providing an efficient and high-quality response for patients. The overcrowding at the emergency departments due to growing demand results in a situation where the demand for ED services exceeds the ability to provide care in a reasonable amount of time. This has led countries to reconsider their health policies in a way to increase their efficiency in their healthcare systems in general and in emergency departments, in particular. As in many countries, there has been a steady and significant increase in the number of patients that seek health services at the emergency departments of state hospitals of Turkey, due to the significant structural reforms in health services since 2003. While meeting this increasing demand, it is ever more important to provide these critical health services efficiently. Therefore, the efficiency of the emergency departments of seven general hospitals run by Istanbul's Beyoglu State Hospitals Association have been analyzed using categorical Data Envelopment Analysis (DEA) models. The analysis of DEA results is supported by a set of statistical methods to make it easier for the hospital administrators to interpret the analysis and draw conclusions. The analysis shows that less-equipped EDs are supported by better equipped, larger EDs, resulting in a hub-and-spoke type of structure among the EDs where "satellite" EDs serve an important referral function and thus evaluating their efficiency without taking the interoperability among these units into account would not be an accurate assessment of their performance.
\end{abstract}

\section{Introduction}

According to the OECD health report, ${ }^{1}$ in 2016, the healthcare expenditures in the world showed the greatest increase rate of the last seven years with an average of $3.4 \%$ and is expected to increase even further in the near future. Although this increase has been the highest one since 2009, the level before crisis is still not reached. The average health expenditures showed an average of 4-6\% increase rate and were greater than the economic growth before 2009. But since 2012, the health expenditures more closely follow the economic growth. During the financial crisis, especially European countries made important reductions in their health expenditures. As a result; in 2017 the per capita health expenditure in Greece was 30\% below its 2009 level (with 2010 prices), and Portugal, Italy and Spain have just reached their levels before the crisis.

In the crisis period, although a similar reduction in the growth of health expenditures was also experienced outside Europe, it managed to stay at least at a positive level. In Korea, the health expenditures continue to increase by $6 \%$ since 2009 and the per capita health expenditure in 2017 is $55 \%$ higher than its 2009 level. However, Australia, Canada, and United States showed continuous growth of health expenditure and their per capita health expenditures is currently 10-20\% higher than their 2009 levels. $^{2}$ On the other hand, China spent $20 \%$, while India and Indonesia spent $10 \%$ below the OECD average.

\footnotetext{
* Corresponding author.

E-mail addresses: canakkan@sabanciuniv.edu (C. Akkan), makaradayi@medipol.edu.tr (M.A. Karadayi), yeliz.ekinci@bilgi.edu.tr (Y. Ekinci), fulengin@sabanciuniv.edu (F. Ülengin),nimet.uray@khas.edu.tr (N. Uray), karaosman5@itu.edu.tr (E. Karaosmanoğlu).

1 www.oecd.org/health.

${ }^{2}$ http://www.oecd.org/health/health-data.htm.
} 
In 2016, the per capita health expenditure of United States was almost three times higher than that of 35 OECD countries, and was $25 \%$ higher than Sweden's, which was second-ranked [1]. When compared with the G7 countries, United States spend $80 \%$ more on health than Germany and two times more than the per capita expenditure of Canada. Health spending in OECD countries is now 9\% of GDP on average ranging from $4.3 \%$ in Turkey to $17.2 \%$ in the United States. The OECD countries spending half or even less of the OECD average expenditure consist of countries such as Poland, Chile and Estonia, the lowest per capita expenditure belonging to Mexico and Turkey. The latter countries show similarity to Russian Federation, South Africa and Brazil in this respect.

In Turkey, the health expenditures showed a consistent growth of $10 \%$ since 2009 and reached 105 billion TL in 2015 [2]. However, despite this growth, in 2017 the health expenditures of the country were $4.2 \%$ of the GDP, $8.9 \%$ below the OECD average [1]. In Turkey, the elder and high-risk age groups grow at a higher rate than the other age groups. As a result, the chronical diseases increase at a faster rate and showed a potential increase in health care demand [2].

Higher health spending is not necessarily a problem when the benefits exceed costs but there is ample evidence of inequities and inefficiencies in health care. At least half of the world's population cannot obtain essential health services, according to a new report from the World Bank and the World Health Organization [3].

On the other hand, emergency departments (ED) of the hospitals are the frontline of health care systems and play a critical role in providing an efficient and high-quality response for patients. A growing demand for emergency care, however, results with an overcrowding experience referring to a situation where the demand for ED services exceeds the ability to provide care in a reasonable amount of time. There has been a dramatic increase in the number of patients visiting the EDs in almost all OECD countries. According to a research (Bercher, 2015), in 2011, the number of patients coming to ED departments in OECD countries constituted $31 \%$ of the population. With its $70 \%$ of the total population, Portugal has the highest number of ED visit/patient. In Spain, Canada, Greece and United States, the number of ED visit/patient constitute $40 \%$ of the population and is, in fact, much higher than the OECD average. In OECD countries, the number of patients visiting OECD countries experienced a growth rate of $2.4 \%$ between 2001 and 2011 . The highest growth rate was seen in Germany, Belgium, England and New Zealand [4]. The patients visiting ED generally consist of very young and very old persons. The aging population in all OECD countries resulted in an increase in the number of patient visiting EDs.

In Turkey, as in other OECD countries, the increase in the number patients in EDs generally results with low satisfaction level of the patients and increases the importance of measuring the performance efficiency of these departments. Despite being the 17th biggest economy in the world in terms of nominal GDP [5], Turkey faces profound social and economic inequalities, too [6,7]. To solve the problems caused by inequality, governments make reforms, including those in health care. In Turkey, the major health care initiative of the recent years, the Health Transformation Program (HTP), was launched in 2003, which mostly aimed to make health care services more affordable for disadvantaged social groups. As part of HTP, healthcare coverage was increased through the General Health Insurance System, 2021 new hospitals were opened in nine years and there was $74 \%$ increase in public health expenses. Accordingly, for Turkey, healthcare expenses as percent of GDP has increased from $2.5 \%$ in 1995 to $5.4 \%$ in 2014 [5].

One of the major improvement programs has been in the accessibility of emergency services and the expansion of 112 Emergency services (ambulance services), which increased the ratio of emergency services in the health expenditures to $1.8 \%$ from $0.3 \%$ in 8 years [8]. In addition to those patients being in critical condition, patients who should normally be treated in polyclinics (outpatients) tend to go to emergency services to accelerate their treatment process and reduce the fees they pay. This reduces the limited capacity of the emergency

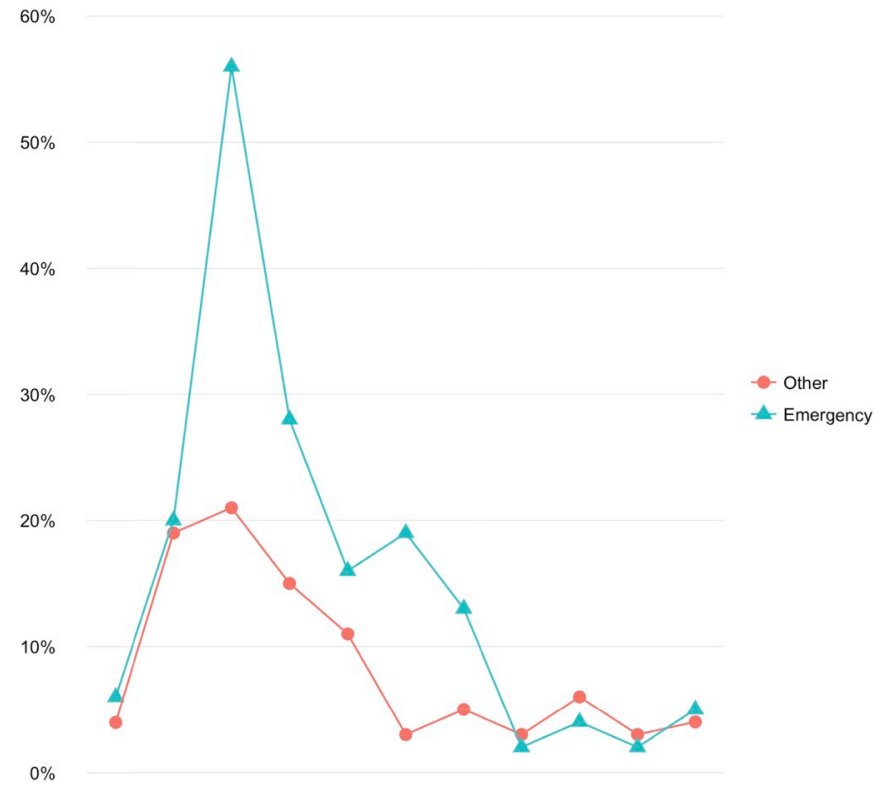

20032004200520062007200820092010201120122013

Fig. 1. Annual increase in the number of patients that apply to the EDs and other departments in Turkey (2003-2014) [9].

services even further and makes the analysis of these units more crucial. As shown in Fig. 1 [9], the number of patients that apply to the EDs increase faster than the other departments in Turkey. The ratio of the emergency patients to all patients increased from $16.79 \%$ in 2002 to $31.76 \%$ in 2013 [9]. According to a news article that appeared in the Turkish newspaper Hürriyet, the number of visits to the emergency units per 100 persons is 130 in Turkey, compared to 45.1 in the US [10].

Administration of the state hospitals in Turkey is done by regional administrative associations ("Kamu Hastaneleri Birliği") that are charged with ensuring the state-owned hospitals of the region provide effective and efficient healthcare services to the citizens. These regional associations, in turn, are organized under the National State Hospitals Administration (Türkiye Kamu Hastaneleri Kurumu). Beyoglu State Hospitals Association (BSHA) is the administrative association that oversees 11 hospitals in central Istanbul. Table 1 provides a list of the selected hospitals, along with statistics on the number of patients (excluded ones are specialized ones, such as a dental hospital). BSHA hospitals, due to the region's geographic centrality in Istanbul, including the main business districts of the city, attract patients that reside outside the region as well. For instance, in 2013, 19\% of the emergency patients in Istanbul were treated by BSHA hospitals; among these patients, $18 \%$ of them reside outside the region.

The aim of this study is to identify the most crucial input and output indicators and to develop models for measuring efficiency in emergency

Table 1

Statistics on the number of patients (2014) at selected BSHA Hospitals.

\begin{tabular}{llll}
\hline Hospital & Acronym & All Patients & Emergency Patients \\
\hline $\begin{array}{l}\text { Research and Teaching Hospitals } \\
\text { Okmeydanı }\end{array}$ & OKRTH & $2,255,969$ & 248,287 \\
Şişli Hamidiye Etfal & SERTH & $1,814,717$ & 760,237 \\
Gaziosmanpaşa Taksim & GTRTH & $1,210,677$ & 145,476 \\
State Hospitals & & & \\
Eyüp & EYSH & 898,567 & 100,932 \\
Kağıthane & KASH & 680,335 & 172,823 \\
Sarıyer İstinye & ISSH & 618,454 & 30,177 \\
Sarıyer İsmail Akgün & SASH & 355,676 & 468,225 \\
\hline
\end{tabular}


services. It empirically tests, using Data Envelopment Analysis (DEA), which of these indicators are the most suitable input/output variables to assess the efficiency and generates models that could be used for further assessment and hence ranking of state hospitals based on their efficiency levels. Being the first study (to the best of our knowledge) that has employed DEA to measure emergency service efficiency, the models offered by this study can yield insights for hospital administrators.

Our main contribution in this paper is the identification of practical and effective input-output variables for measuring efficiencies of EDs. In most practical situations, the administrators would need to analyze the efficiency of EDs in similar environmental conditions (such as same city, similar socio-economic environments), this would limit the number of EDs to be analyzed in an efficiency analysis. Hence, for an effective use of DEA, it is inevitable to have a rather restricted number of input and output variables. Our work has specifically shown that categorical DEA which employs a well-defined level category system for EDs is a viable approach to efficiency measurement. Furthermore, our fieldwork supported with the DEA analysis has shown that referrals from one ED to another is an important output of some EDs, which led us to the conclusion that, a hub and spoke system is a good strategy to provide effective emergency services. In such a hub-and-spoke system, less equipped smaller satellite EDs are supported by better equipped "hub" EDs.

The rest of the paper is organized as follows. Section 2 provides the literature review on the efficiency measurement in emergency services and emphasizes the reason for selecting Data Envelopment model to analyze the efficiency of emergency departments in this research. It also highlights the inputs/outputs variables used in the data envelopment models developed so far. Section 3 explains the methodology used in this research. Section 4 provides information about the proposed categorical DEA framework. Section 5 interprets the model results and uses ALSCAL and principal component analysis to select the best DEA model for this study. Finally; conclusions and further suggestions are given.

\section{Efficiency measurement in emergency services and the use of DEA}

Generally, efficiency in the healthcare sector is analyzed using either parametric (e.g. a regression-based Stochastic Frontier Analysis, SFA) or non-parametric methods (e.g. Data Envelopment Analysis, DEA). Although there are several conceptual and practical differences between SFA and DEA analysis; the basic difference is the number of outputs being restricted to one in SFA. On the other hand, SFA allows for the calculation of errors and necessitates to find the functional form of the data. Despite the fact that SFA is the most widely used method in the healthcare sector, in recent years, there has been an increase in the use DEA together with parametric methods such as regression analysis [11]. The main reason of this is that DEA can handle effectively multiple outputs in the transformation process. Moreover, DEA does not require knowledge of the functional form that links inputs to outputs, allows identification of efficiency targets for performance improvement of inefficient Decision Making Units (DMUs) and provides more detailed feedback on areas of inefficiency. The main idea behind DEA is to provide a methodology whereby, within a set of comparable DMUs, those exhibiting best practice can be identified, and will form an efficient frontier. In a given instance with $n$ DMUs, where each DMU uses varying amounts of $m$ different inputs to produce $s$ different outputs, the relative efficiency of a DMU is computed as the ratio of its total weighted output to its total weighted input. DEA evaluates the relative efficiency of one DMU at a time over all other DMUs by determining the most favorable weights from the viewpoint of that, "target", DMU. In DEA models there are two possible orientations to efficiency analysis: (1) input-oriented, where one targets to minimize the input used to produce given output levels for each DMU and (2) output-oriented, where one targets to produce the highest possible output levels for a given input usage for each DMU. Furthermore, another differentiator of DEA models is whether they assume constant returns to scale (CRS) or variable returns to scale (VRS). The most well-known version of the CRS models is so-called CCR [12] model, and the most well-known version of the VRS models is the BCC [13] model.

In this study, DEA is selected over alternative techniques not only because DEA is used more widely, but also DEA is more appropriate for the analysis of efficiency in the health industry since the DEA framework provides an analytical tool for the determination of effective and ineffective performance of DMUs producing several types of services (outputs) using several inputs [14-20]. DEA provides the distances between non-efficient units and the use of frontier based on efficient units permits the assessment of a productive efficiency using multiple inputs and outputs, when production factors operate with both variable returns to scale (VRS) or constant returns to scale (CRS) [11,15].

Earlier studies that have used DEA for efficiency assessment in healthcare do not generally focus on EDs. To the best of our knowledge, quantitative efficiency analysis research done on the emergency units of hospitals is very scarce [21]. This is despite the fact that in both some developed economies such as the U.S. [22] and developing economies such as Turkey (see Fig. 1) the number of patients applying to the emergency departments (EDs) has been increasing. Kang et al. [21] analyze the data of 976 EDs in the US. They use a two-stage DEA approach to look into both scale efficiency and technical efficiency and use a multivariate logistic regression model to identify exogenous factors affecting the technical efficiency of EDs. Their model uses three input (number of beds, physician and nurse working hours per day) and three output (number of patient visits per day, reciprocal of the rate of left before treatment complete, and the number of EKG procedures per 100 patients) variables. They use the classical CCR and BCC models. They identify which exogenous variables (such as type, location, trauma level) have an impact on efficiency.

Most of the DEA-based research conducted so far focus on the overall hospital efficiency and there are only a few studies which concentrate on a specific department (e.g. Ref. [23] - primary care units [24]; - trauma facilities [25]; - gynecology departments). Another common feature of the existing studies is that they use yearly data for the analysis. However, there can be some seasonal effects on the efficiencies of the hospitals/departments.

In Turkey, research on the use of DEA to analyze the efficiency of hospitals is limited. Ersoy et al. [26] performs an efficiency analysis of 573 state hospitals, based on 1994 data, and using input-oriented DEA. Sahin \& Ozcan [14] compares the efficiency of hospitals operating in different cities and analyze the reasons behind the inefficiency issues. Temür \& Bakırc1 [27] analyze and compare the performance of 846 public hospitals in 81 cities for the 2003-2006 period. Cakmak et al. [25] investigate the efficiency of 43 gynecology departments of Turkish hospitals using DEA. Bayraktutan et al. [28] use the same method to analyze the efficiency of 21 chest diseases hospitals. Sahin et al. [29] analyzes the efficiency of 352 public hospitals for the 2005-2008 period using fixed and variable return to scale DEA. Ozgen \& Sahin [30] uses cross-sectional data from the 2008 Turkish Statistical Yearbook of Dialysis to analyze the efficiency of the dialysis sector in Turkey using DEA. Bilsel \& Davutyan [31] tests the operational efficiencies of 202 hospitals in Turkey using DEA with "directional distance" approach to identify improvement in both input and outputs.

This study differs from the existing studies in two ways. Firstly, it focuses on a specific department. Secondly, it conducts the analysis seasonally. Furthermore, in terms of methodology, we have utilized a regression-based residual analysis to identify statistically significant deviations in different DEA models' ranking of DMUs. With this approach, we were able to identify the importance of including the referrals (from one ED to another hospital's ED) as an output variable.

Since the DEA analysis allows multiple outputs as well as multiple inputs, we have reviewed the literature on DEA modeling done for 
hospitals between 1984 and 2016, to see the input and output variables commonly used. We grouped the variables into general variable categories; this taxonomy reveals the complexity and the importance of efficiency measurement in health services. We limited our attention to those with at most eight input/output variables, as this would be a more relevant benchmark for our study in emergency units with limited data availability. In this taxonomy study of DEA-based hospital technical efficiency studies, we used the input/output categories proposed by O'Neill et al. [32]. We used O'Neill et al. [32] since it is the most comprehensive review which categorizes the input/output variables used in DEA models for evaluating the efficiency of hospitals. The most recent review of efficiency measurement in healthcare [109], only reviews the methodologies used and does not show which study uses which variables (input-output) in detail. We based our review on O'Neill et al.'s [32] study to define more aggregate categories and complemented this study by adding publications done between 2004 and 2016, adding quality measures as a new category and pooling all other unaccounted variables into the others category, resulting in 9 input and 10 output categories (it should be noted that we will not consider quality as a category in this study, as DEA considers in principle the incorporation of physical measures to evaluate the economic perspective). In Web of Science database, we searched for articles published between 2004 and 2016 (the years between 1984 and 2004 were earlier analyzed by O'Neill et al. [32] using the keywords "hospital, healthcare, efficiency, DEA". Moreover, we limited our attention to those with at most eight input/output variables, as this would be a more relevant benchmark for our study in emergency units with limited data availability. For the surveyed articles, Table 2 provides summary statistics on the number of the input/output variable categories used per DEA model. Based on these statistics, one could argue that having 3 input and 3 output variables is quite typical for hospital DEA analysis.

Table 3 provides the number and percentage of the reviewed articles (out of a total of 71 articles) that use a specific input/output variable category in their DEA model (see Appendix 1-A and 1-B for a complete list with a detailed breakdown of categories used in the model of each article). This table shows that most common input variable category used for hospitals is the number of beds, and the second group of categories is the number of staff (physicians, nurses, clinical and non-clinical staff). Number of beds is commonly accepted as a very strong indicator of hospital size and the number of the staff represents the medical labor capacity of the hospital. The third group of variable categories includes the cost-based variables. The most common output variable category used for hospitals is the number of medical visits. The other variables frequently used are about the number of patients served (inpatient days, discharges, surgeries for inpatients; number of visits, emergency services etc. for outpatients). The outputs used in this study are total number of emergency patients and total number of referrals from the ED; which is consistent with the literature. On the other hand, the inputs used in the study are the number of beds in the ED and MoH level classification of the EDs. As discussed in the following sections in more detail, level classification is a good proxy measure for capacity and capabilities of ED. From this perspective, the number and the nature of input and output variables we have used are consistent with the literature review, especially considering that we are considering only one hospital unit; namely ED. The total number of referrals from the ED comes

Table 2

Summary statistics on the number of input/output variable categories in DEA models.

\begin{tabular}{llll}
\hline & \# Input Var. Cat. & \# Output Var. Cat. & Tot. \# Var. Cat. \\
\hline Average & 3.48 & 2.86 & 6.34 \\
Median & 3 & 3 & 6 \\
Min & 1 & 1 & 4 \\
Max & 6 & 6 & 9 \\
\hline
\end{tabular}

Table 3

Usage frequency of main hospital variables in DEA models.

\begin{tabular}{llll}
\hline Input Variables & $\begin{array}{l}\text { Nbr (\%) of } \\
\text { articles }\end{array}$ & Output Variables & $\begin{array}{l}\text { Nbr (\%) of } \\
\text { articles }\end{array}$ \\
\hline No. beds & $61(86 \%)$ & No. medical visits & $55(77 \%)$ \\
No. physicians & $39(55 \%)$ & No. cases & $3(4 \%)$ \\
No. nurses & $27(38 \%)$ & No. patients & $16(23 \%)$ \\
No. clinical staff & $29(41 \%)$ & No. surgeries & $25(35 \%)$ \\
No. non-clinical staff & $24(34 \%)$ & No. inpatient days & $31(44 \%)$ \\
Capital invest. \& op. exp. & $30(42 \%)$ & No. admissions & $6(8 \%)$ \\
Labor costs & $5(7 \%)$ & No. discharges & $22(31 \%)$ \\
Supply \& non-labor costs & $10(14 \%)$ & No. services & $12(17 \%)$ \\
Other & $16(23 \%)$ & Quality measures & $3(4 \%)$ \\
& & Other & $15(21 \%)$ \\
\hline
\end{tabular}

from the field study conducted in Istanbul. The input variables chosen for the study will be presented in the next session along with the reasons for their choices.

\section{Methodology}

Our research was carried out for the hospitals of Beyoglu State Hospitals Association (BSHA) in Istanbul. The flowchart summarizing the main steps of our research process is depicted in Fig. 2.

Due to the nature of the analysis unit, seasonality characteristic of the study and the requirements of DEA, it was necessary to determine the most critical input and output variables which are relevant across all the hospitals in the study and for which the related data can easily be collected without any missing value. Because of the limited number of hospitals, a field research including a few stages was planned as the early stage of the research process. First, an extensive literature survey that mostly focuses on empirical studies on the effectiveness of hospitals in general, and EDs in particular, was carried out to accomplish the objective cited above. A list of fifty indicators of the efficiency that are relevant in the health industry was derived from the literature. Because of the inadequate number of studies on the efficiency of EDs in the literature as well as the need for discovering the most crucial and country-specific indicators, an in-depth interview with the Head of Business Development Unit of BSHA was also conducted. This in-depth interview indicated that the recent report of the study on the issue of efficiency prepared for the Ministry of Health and related institutions including BSHA consist of six main categories of efficiency indicators. These are medical; administrative; financial; quality, satisfaction,

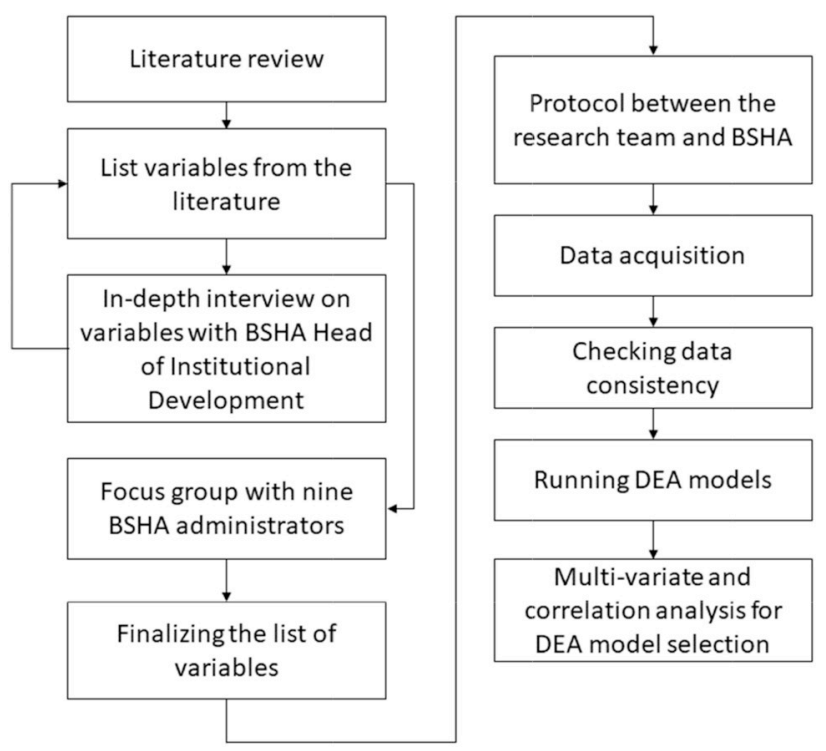

Fig. 2. Flowchart of the research process. 
personnel, and patient security; training and finally evaluation of observers. The in-depth interview which lasted almost two hours put forward that each of these dimensions of effectiveness includes at least several indicators and almost 40 input variables in total can be considered in the effectiveness of ED in a health system similar to Turkey. This in-depth interview was also an opportunity to get information from one of the experienced industry experts about the perceived importance of those indicators.

Due to the diversions of the dimensions and both the type and number of indicators considered to measure efficiency in the industry from the literature, a focus group discussion with nine administrators of BSHA for two and a half hours was carried out in order to reach a consensus. A list of 60 indicators as variables by combining both those in the literature and those discussed in the in-depth interview was evaluated in this process. Five categories which are mostly used in the literature were given as the framework to the participants. During the focus group discussion, experts' opinions were inquired regarding the appropriateness of using these indicators in the context of emergency units, and the availability and reliability of the data related to these indicators. We also asked the experts about the relevance and importance of using the variables as inputs/outputs in the context of measurement of efficiency. Furthermore, the focus group session also gave an opportunity to discuss and reallocate the indicators in the more meaningful dimensions or categories.

Table 4 indicates five categories and number of appropriate indicators allocated to each category. It is interesting to note that although the category of time/duration is relevant in the literature, it was not found significant and valid in the focus group. On the other hand, almost all the members agreed that resources, patient-based category and "other" category of indicators are perceived as the most crucial categories of efficiency measurement of ED.

As a summary, the result of the focus group discussion, 50 of total 60 indicators were found meaningful and significant to take into consideration for efficiency measurement of ED. However, these 50 indicators differ from each other in terms of their importance in the role of measurement of the efficiency of ED.

After the two-stage comprehensive qualitative field research, we identified four variables which are the most critical and related data available that could be used to evaluate efficiency of the EDs. These were ED level certified by the Ministry of Health $(\mathrm{MoH})$, total number of beds in the ED, the total number of emergency patients, and the total number of referrals from the ED. Among these, the level of EDs is probably the most important variable because, as discussed in the next section, its use affected the type of DEA model used and distinguished our model from most of the other models in the literature. Turkish $\mathrm{MoH}$ categorizes the EDs of hospitals depending on their medical competencies and capabilities, and the infrastructural characteristics [33]. Level 1 EDs are those that satisfy the minimum requirements. To be a Level $2 \mathrm{ED}$, a department would need to have special medical imaging facilities, decontamination rooms, etc. To be further classified as a Level 3 , a department would have to have an emergency lab dedicated to the $\mathrm{ED}$, a special trauma room, etc. There are also requirements on the number of medical personnel (doctors and nurses) assigned to the departments, medical services available to the ED (e.g. surgeons available
$24 \mathrm{~h}$ of the day within the hospital), security services in the EDs, characteristics of the resuscitation room, the medicines/drugs to be available at the department. In addition, there are physical characteristics that determine the level of a department. Among these, we have the location/accessibility characteristics, the size of the medical/treatment areas (in square meters), and the number of beds. Children's emergency (pediatric EDs/departments) are also evaluated and assigned a level. These level assignments are done by a commission which does a site visit. In total there are 43 items under the physical characteristics heading, 39 items under the personnel and services heading, 16 sub-categories in the medical equipment and hardware heading, 15 sub-categories under the resuscitation room heading, and 30 sub-categories under the medicines/drugs heading. Thus, ED level is strongly related to the number of staff and costs (including capital expenditures). For example; for level 1 ; the size of the medical/treatment area should be at most $400 \mathrm{~m}^{2}$, whereas for level 3 this is at least $800 \mathrm{~m}^{2}$. Similarly, to be a level $3 \mathrm{ED}$, the unit must have a dedicated intensive care unit; and the number of physicians should be at most 2 for a level 1 unit while at least 4 for a level 3 unit.

One of the challenges of empirical research in healthcare services is access to sufficient and reliable data. In the context of Turkish state hospitals, hierarchical classification of the EDs is both very reliable and strongly related to some key characteristics of these units that define their capabilities and capacities. Similar hierarchical classification systems exist in other healthcare systems as well. Therefore, the modeling approach developed here could prove to be beneficial in such systems, too.

As discussed in Section 2, for hospital efficiency analysis the most common input categories are number of beds, number staff, and costs (including capital expenditures). This is consistent with the variables used in our model, namely number of beds and ED level, since ED level is strongly related to the number of staff and costs (including capital expenditures).

\section{Proposed categorical DEA framework}

As discussed in the previous section with our field research it became evident that the level of the ED was a reliable and comprehensive indicator of the capacity and capability of the EDs. The ED level was mapped to the values of the categorical variable as follows: the categorical variable was set to 1 and 2 for ED Level 1 and Level 2, respectively. When ED Level is 3, the categorical variable was set to 3 if the ED had a Level 2 pediatric emergency and it was set to 4 when it had a Level 3 pediatric emergency. The number of beds in each ED showed significant variation among hospitals with the same level, and thus it was decided to include that as an input as well.

When some of the variables are categorical, Categorical DEA models [34] are used. In this context, DMUs are divided into sub-groups based on the categorical variables. If there are $L(1,2, \ldots, L)$ levels of a categorical input variable, these $L$ values divide the DMUs into subgroups such that $D=\{1,2, \cdots, n\}=D_{1} \cup D_{2} \ldots \cup D_{L} \quad$ where $D_{k}=\{i \mid i \in D$ and input value is $k\}$ and $D_{k} \cap D_{j}=\varnothing$ for $j \neq k$. Each DMU in category $k$ is evaluated based on the envelopment surface which is defined by the DMUs that are in categories $1, \cdots, k([34,35])$.

Table 4

Efficiency indicators discussed in the focus group process.

\begin{tabular}{|c|c|c|}
\hline Category & \# Variables & Examples \\
\hline Financial & 4 & Total assets, labor cost, non-labor costs, cost of medicine used for treatment \\
\hline Time/duration & - & - \\
\hline Environmental & 9 & Population, ratio of over 65 age in the population, private hospitals nearby, university hospital nearby \\
\hline Resources & 23 & No. emergency beds, no. doctors, paramedic ratio, no. beds per room \\
\hline Patient-based & 11 & No. patients, post-surgery inpatient days for ED patients, patient satisfaction \\
\hline Other & 3 & ED level, no. referrals from the ED, employee satisfaction surveys \\
\hline Total & 50 & \\
\hline
\end{tabular}


Level designations provided by the Ministry of Health makes the categorical DEA models an appropriate approach to measuring efficiencies of the EDs. [34], in their development of categorical DEA models, propose that "when some factors in an efficiency analysis are $0-1$ variables, we have to use a method for insuring that the composite reference members be constructed from DMUs which are in the same category or possibly from those in a category which is deemed to be operating in an even more difficult or unfavorable situation". In this regard, we employ four different categorical DEA models as listed below [35]:

- Input Oriented CCR Model with Categorical Variables (CAT-I-C)

- Output Oriented CCR Model with Categorical Variables (CAT-O-C)

- Input Oriented BCC Model with Categorical Variables (CAT-I-V)

- Output Oriented BCC Model with Categorical Variables (CAT-O-V)

Two variables were tested as outputs: (1) the total number of patients served, and (2) the total number of referrals. Other than these inputs and outputs, we had three other potential inputs (number of doctors, number of interns/assistants, number of operating rooms in the ED) and one other output (number of operations done in the ED's operating rooms) in the short list, which we decided not to use. Upon our discussions with the administrators at BSHA, the number doctors in the hospital was not deemed to influence the chosen outputs. It could have been used as a measure of hospital size, but it was decided that ED level and the number of beds in the ED provided enough information regarding the size of the hospital. On the other hand, the number of operations in the EDs was often equal to 0, thus we decided not to use this variable (both because of the positivity assumption of DEAs and was judged to be a small fraction of the workload that the EDs faced).

BSHA provided us monthly data and we aggregated this into seasonal data and treat each ED for each season as a single DMU (seasons were defined as four tri-monthly periods, starting with December, March, June, and September). There were two reasons for making this choice. First, we wanted to see whether there was any seasonal pattern in efficiency. Second, since the scope of the study was limited to seven hospitals, using seasonal data allowed us to have a sufficiently large number of DMUs to have a reliable DEA analysis. It is well known that for ensuring good discriminatory power out of the CCR and BCC models, there must be a minimum number of DMUs [36] establish a rule that the number of units should be at least twice the number of inputs and outputs considered).

To find the most appropriate input-output set, two different variable sets, VARSET 1 and VARSET 2 were used (see Table 5). Generally, CRS model is widely used for performance analysis in the healthcare field [36]. However [37], states that efficiencies of DMUs could be evaluated both using CRS and VRS assumptions. Therefore, both CRS and VRS assumptions are tested in this study. These models were solved using DEA-SOLVER-V8 to obtain the results discussed next in Section 5.

\section{Analysis of the results}

\subsection{Multi-dimensional analysis}

One of the crucial points in DEA studies is to select the appropriate input-output combination. For this purpose, we first used two

Table 5

Data models tested.

\begin{tabular}{lll}
\hline Variables & VARSET 1 & VARSET 2 \\
\hline ED Level Category & Input & Input \\
Total number of emergency patients & Output & Output \\
Total number of beds in the ED & Input & Input \\
Total number of referrals from the ED & N/A & Output \\
\hline
\end{tabular}

Table 6

Notation for model characteristics.

\begin{tabular}{lll}
\hline & Description & Code \\
\hline $\begin{array}{l}\text { Input Variables } \\
\text { Level of ED (X1) }\end{array}$ & ED Level Category \\
$\begin{array}{l}\text { Number of beds (X2) } \\
\text { Output Variables }\end{array}$ & Total number of beds in the ED & B \\
Number of patients (Y1) & Total number of emergency patients & 1 \\
Number of Referrals (Y2) & Total number of referrals from the ED & 2 \\
Models & Constant Returns to Scale & \\
CRS & Variable Returns to Scale & C \\
VRS & Input Oriented DEA Model & V \\
Output Oriented & Output Oriented DEA Model & I \\
\hline
\end{tabular}

methodologies, namely ALSCAL and Principal Component Analysis (PCA) (see Refs. [38,39]). Scaling models measure the proximity between pairs of objects. Proximities are calculated between models in our study in order to cluster a variety of DEA specifications. Similarly, PCA reduces the dimensions of the data used. Both ALSCAL and PCA permit the joint graphical representation of models and DMUs [39].

We clustered 8 different DEA models (generated by using different input-output combinations and different DEA methodology assumptions as given in Table 6) and 28 DMUs, using ALSCAL and PCA. Since we have $28 \times 8$ efficiency scores, clustering was done to help us to differentiate the models; and hence the input/output combinations and DMUs. The aim of using both methods was to clarify the relationship between models and DMUs. To identify the most appropriate model, we used the efficiency scores of various DEA models (see Appendix 2), which are denoted by acronyms defined in Table 7 using the notation (codes) defined in Table 6.

\subsubsection{ALSCAL}

ALSCAL is a Multidimensional Scaling (MDS) technique. ALSCAL is a flexible technique which can produce metric and nonmetric scaling with or without individual differences models. After analyzing the data given in Appendix II we got a stress measure of 0.00458 (very good fit) and an R-square of 0.999 (illustrating that $99.9 \%$ of variance in the model is explained by the two dimensions). S-stress is a measure of fit ranging from 1 (worst possible fit) to 0 (perfect fit). This fit shows that we can group the variables into two dimensions. The stimulant coordinates in Table 7 is the weights each model has in each dimension. There are two dimensions that pull apart these variables. For example, $\mathrm{AB} 12 \mathrm{VO}$ is strong on dimension 1 while the strongest models on dimension 2 ( $\mathrm{AB} 1 \mathrm{CI}$ and $\mathrm{AB} 1 \mathrm{CO})$ do not take very high values.

As can be seen in Fig. 3 CRS models are on the right side of the ycoordinate and VRS models are on the left side. This result shows that ALSCAL model differentiates eight DEA models based on whether they use constant or variable returns to scale. Furthermore, AB12VO seems to be very much alone and $\mathrm{AB} 1 \mathrm{CI}$ and $\mathrm{AB} 1 \mathrm{CO}$ are clumping models. $\mathrm{AB} 12 \mathrm{CI}$ and $\mathrm{AB} 12 \mathrm{CO}$ are also clumping. This result reveals that for CRS, input and output-oriented models do not discriminate. The basic

Table 7

Stimulus Coordinates (ALSCAL results).

\begin{tabular}{llll}
\hline Stimulus Number & \multicolumn{2}{l}{ Dimension } & 2 \\
\cline { 2 - 4 } & Stimulus Name & 1 &,- 3689 \\
\hline 1 & AB1CI & 1,5502 &,- 3689 \\
2 & AB1CO & 1,5502 &,- 3186 \\
3 & AB1VI &,- 9692 &,- 0948 \\
4 & AB1VO & $-1,5540$ &, 5035 \\
5 & AB12CI & 1,1452 &, 5035 \\
6 & AB12CO & 1,1452 &,- 0769 \\
7 & AB12VI & $-1,1503$ &, 2211 \\
\hline
\end{tabular}




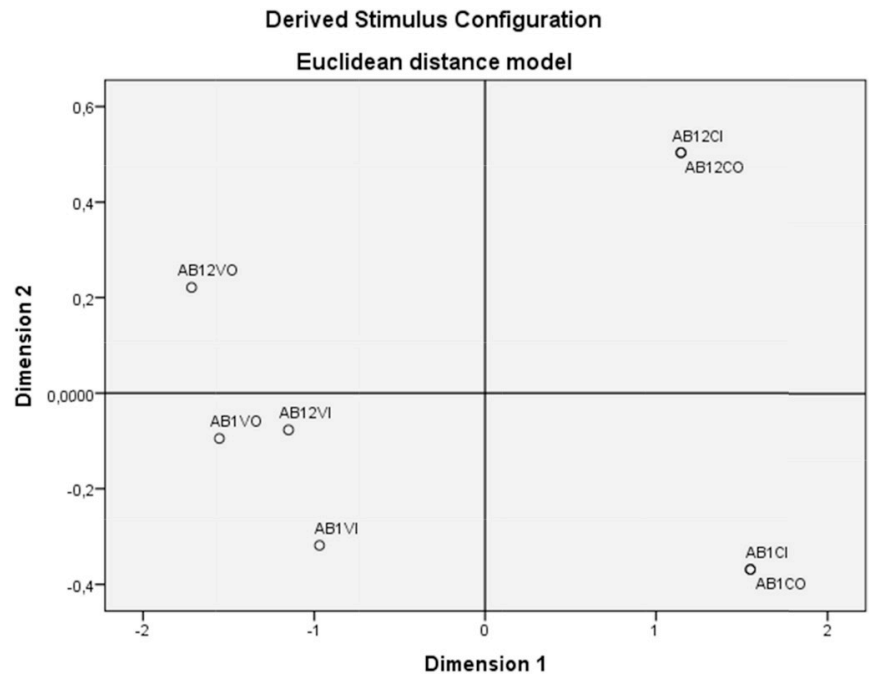

Fig. 3. ALSCAL-common map.

differentiation is obtained through the returns to scale assumption.

\subsection{Principal component analysis}

Principal Component Analysis (PCA) is a data reduction technique [40], which reduces the dimensions of the data used. As in ALSCAL, PCA permits the joint graphical representation of models and DMUs [39].

Table 8 shows the component loadings which have been derived by using Varimax with Kaiser Normalization [41]. The results reveal that eight models have positive loadings in both principal components. Two components explain the variance of the data since the cumulative loading of the first two components has cumulative variance of $94.99 \%$. Therefore, the first two components provide an adequate representation for the data. The first principal component is related to constant returns to scale assumption of DEA model, while the second principal component is related to variable returns to scale assumption. This is consistent with the main finding from the ALSCAL model.

For each DMU, component scores for the first and second principal components have been calculated and plotted in a graph (see Fig. 4). The DMUs that achieve efficiency scores close to $100 \%$ are to be found at the extreme right-hand-side of the first principal component and these high-efficiency scores are obtained by CRS models. These DMUs are SERTH (spring) and SASH (all seasons). At the other extreme of the second principal component, we find DMU SERTH (summer, fall, and winter) which have very low-efficiency scores and they are obtained by VRS models. Looking into the results in Appendix II, we see that these DMUs achieve low efficiencies under all models.

The results of both ALSCAL and PCA analysis reveal that the dominant factor that discriminates the various DEA models in this study

Table 8

Component loadings.

\begin{tabular}{lll}
\hline & \multicolumn{2}{l}{ Component } \\
\cline { 2 - 3 } & 1 & 2 \\
\hline AB1CI & $\mathbf{0 , 9 2 4}$ & 0292 \\
AB1CO & $\mathbf{0 , 9 2 4}$ & 0292 \\
AB12CI & $\mathbf{0 , 9 2}$ & 0,3 \\
AB12CO & $\mathbf{0 , 9 2}$ & 0,3 \\
AB1VI & 0,393 & $\mathbf{0 8 9 6}$ \\
AB12VI & 0,365 & $\mathbf{0 9 1 3}$ \\
AB12VO & 0,26 & $\mathbf{0 , 9 3 6}$ \\
AB1VO & 0,224 & $\mathbf{0 9 6 5}$ \\
\hline
\end{tabular}

is the assumption of constant or variable returns to scale.

\subsection{Analysis of appropriate input-output configuration}

To identify the most appropriate variables, we used the rankings of the efficiency scores rather than the efficiency scores since these rankings are less sensitive to small deviations in the data and the hospital association administrators were more interested in the relative ranking of the hospitals. We compared the rankings of the efficiency scores of the DMUs obtained by VARSAT 1 (along x-axis, denoted as Model 1) versus by VARSAT 2 (along y-axis, denoted as Model 2) using a scatter plot, where each marker corresponds to a DMU and color coding is used to distinguish DMUs corresponding to different seasons (Fig. 5 through Fig. 10).

\subsubsection{CRS model results}

Figs. 5 and 6 present the rankings for both CAT-O-C and CAT-I-C models for 2014 and 2013, respectively, since these two models yielded the same efficiency scores. Fig. 5 shows that VARSET 1 and VARSET 2 provide, for the most part, a consistent ranking of the hospitals in 2014. Only ISSH shows inconsistent results in VARSET 1 and $2((23,10)$ for fall and $(17,8)$ for summer), being significantly more efficient in VARSET 2. Studentized residual analysis for regression models was used to identify statistically significant outliers. It is generally accepted that if the absolute value of the studentized residual is close to or greater than 3 , the corresponding data point is an outlier. For instance, in CATI-C and CAT-O-C 2014 the studentized residual values were -2.99 for fall season and -2.1 for summer season of ISSH. The main characteristic of ISSH is that it is relatively small "neighborhood" hospital with level $2 \mathrm{ED}$; hence it must make a lot of referrals. These two DMUs (ISSH fall and summer) become fully efficient with VARSET 2, because VARSET 2 takes referrals as an output.

Fig. 6 shows that for 2013, VARSET 1 and VARSET 2 provide consistent rankings, as they did for 2014 data. ISSH is again significantly more efficient in VARSET 2 compared to VARSET 1 in two of the four seasons (points $(19,9)$ and point $(10,1)$ with studentized residual values equal to -2.71 and -2.57 , respectively). We should also note that the effect of using VARSET 2 on the ranking of ISSH is consistent in both years.

\subsubsection{VRS model results}

As was the case for the CRS models, Fig. 7 shows that CAT-I-V model for 2014 provides consistent rankings of the hospitals for VARSET 1 and VARSET 2 with two outliers (points $(9,1)$ and $(23,1)$ ). The studentized residual value for KASH is -4.28 ; since this is a strong outlier, after omitting this data point and running the studentized residual analysis again the studentized residual for ISSH-Spring is found to be -2.75 . KASH, like ISSH, is a "neighborhood" hospital.

For 2013 we see a very similar picture in Fig. 8. VARSET 1 and VARSET 2 provide a consistent ranking of the hospitals with a few outliers. Okmeydanı RTH (OKRTH) became fully efficient in 2013 spring (point $(15,1)$ ) and ISSH became fully efficient in fall (point $(14,1)$ ) and spring (point $(12,1)$ ) when we use VARSET 2 . The studentized residual values for OKRTH-spring, ISSH-fall, and ISSH-spring are $-2.63,-2.45,-2.08$, respectively. OKRTH case is due to the Gezi Park protests in late May 2013, which lead to violent clashes between the police and the protesters in Okmeydanı neighborhood and OKRTH was flooded with wounded people some of whom had to be referred to other hospitals. We see that VRS model CAT-I-V captured the effect of Gezi Park protests, whereas, CRS models did not. Considering the importance and magnitude of Gezi Park protests, we can conclude that VRS model could be more appropriate for evaluating the relative efficiency of the EDs of the hospitals of BSHA.

Like the other DEA models, Fig. 9 shows that CAT-O-V models provide consistent rankings of the hospitals for 2014. The outlier $(19,1)$ corresponds to KASH, becoming fully efficient with VARSET 2 


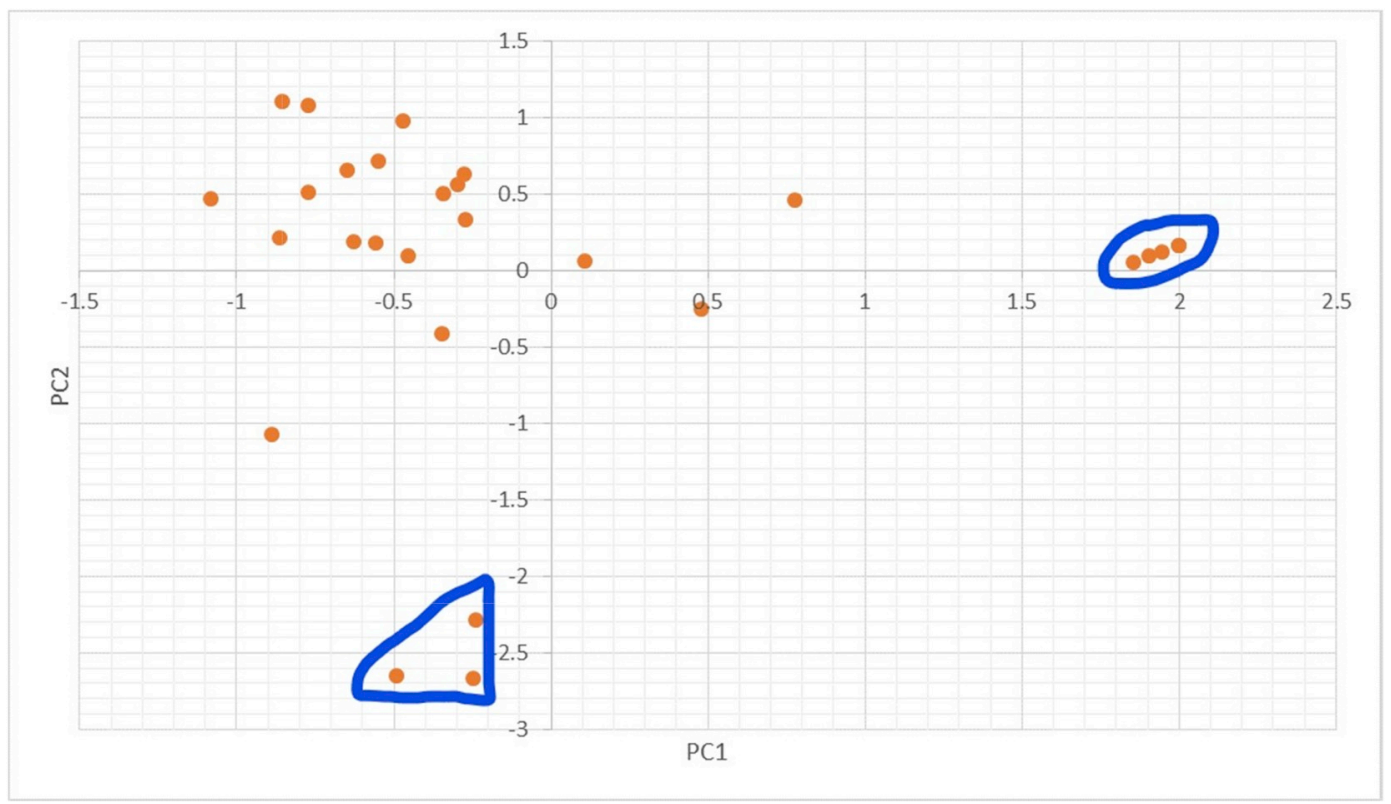

Fig. 4. Component scores for the first and second principal components.

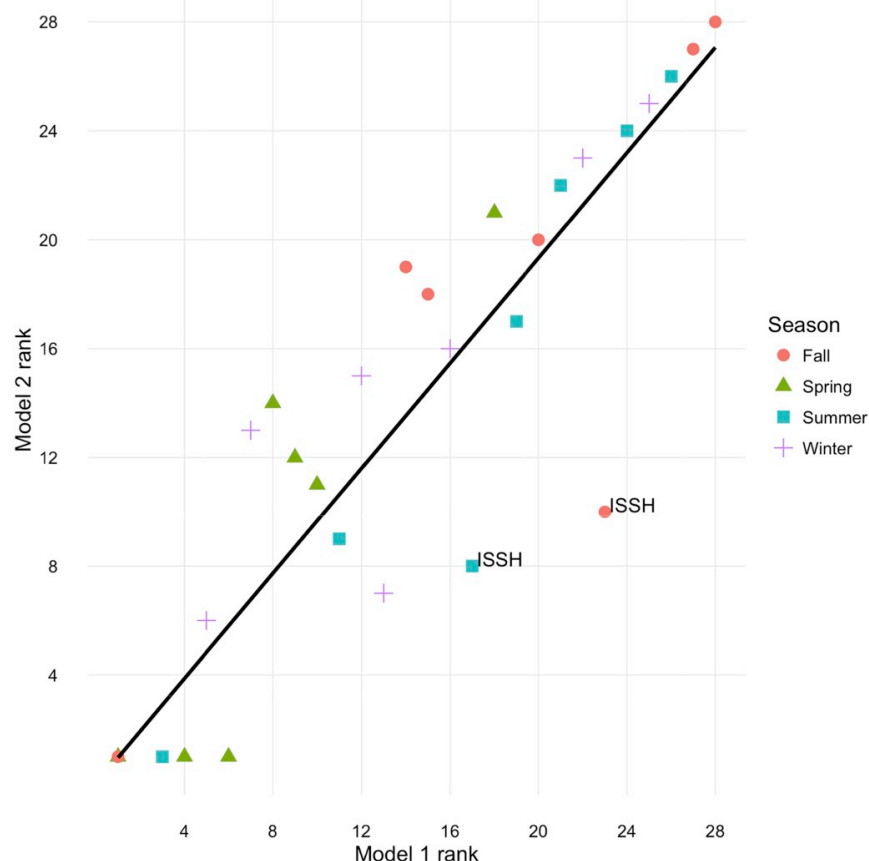

Fig. 5. CAT-O-C 2014 and CAT-I-C 2014 efficiency score rankings.

(studentized residual is -2.82). 2013 data (Fig. 10) provides a similar picture to that of 2014 with the exception that ISSH in fall appears as a significant outlier, becoming fully efficient in VARSET 2 whereas it ranked 15th in VARSET 1 (Studentized Residual $=-2.64$ ).

Fig. 5 through Fig. 10 show that seasons do not have a strong effect on efficiency rankings as high and low rankings are more or less evenly distributed across seasons for all models in both years. Considering the model results and interpretations above, we decided to test the null hypothesis which claims that the VARSET 1 and VARSET 2 efficiency scores for the small neighborhood or "satellite" hospitals are equal. The reason we develop this hypothesis is that ISSH and KASH usually become fully efficient in VARSET 2 . The p-values for the two-tailed $t$-test for the differences of VARSET 1 and 2 for CAT-I-V, CAT-O-V, CAT-I-C, CAT-O-C (using the efficiency scores of all four seasons for both years)

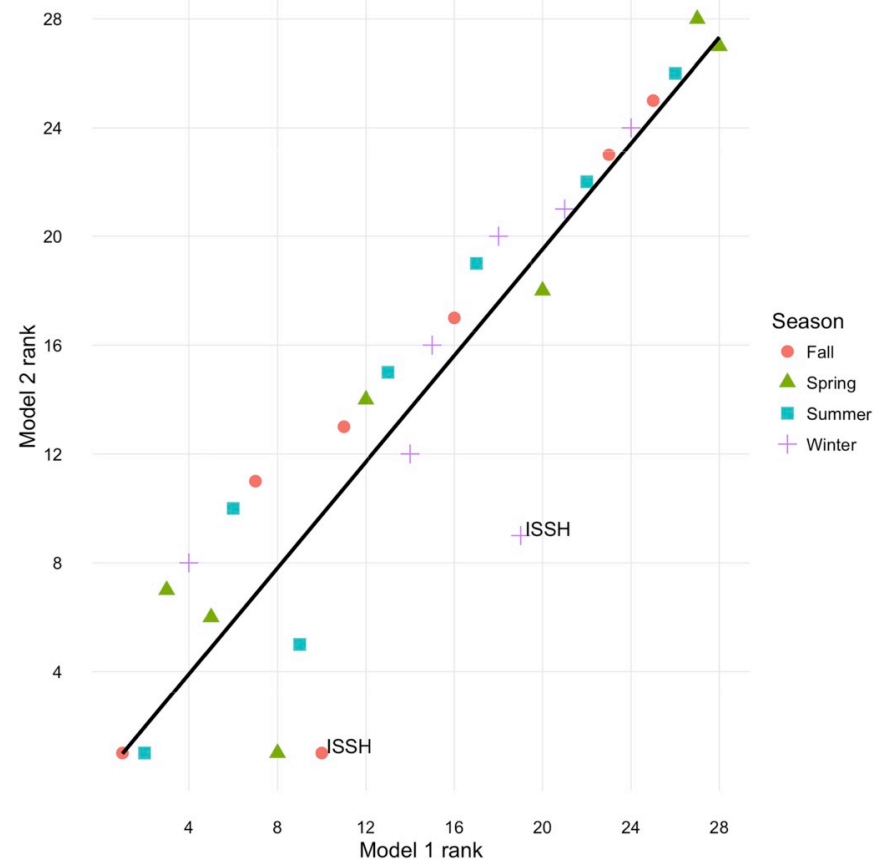

Fig. 6. CAT-O-C 2013 and CAT-I-C 2013 efficiency score rankings.

were found to be $0.00827,0.004911,0.00194,0.00194$ respectively. The results show that the efficiency scores in VARSET 1 and 2 are significantly different for ISSH and KASH. This means that for satellite hospitals such as ISSH and KASH, the number of referrals makes an important impact on efficiency scores.

\section{Conclusions and further suggestions}

In this research, we developed a methodology to test the appropriateness of a set of DEA models to measure the efficiency of some of the busiest emergency departments in Istanbul. Our methodology, built on a set of easy to interpret graphical analysis and multivariate statistical techniques, helped us determine the most appropriate set of inputs and DEA model to analyze the efficiency of these EDs. These techniques 


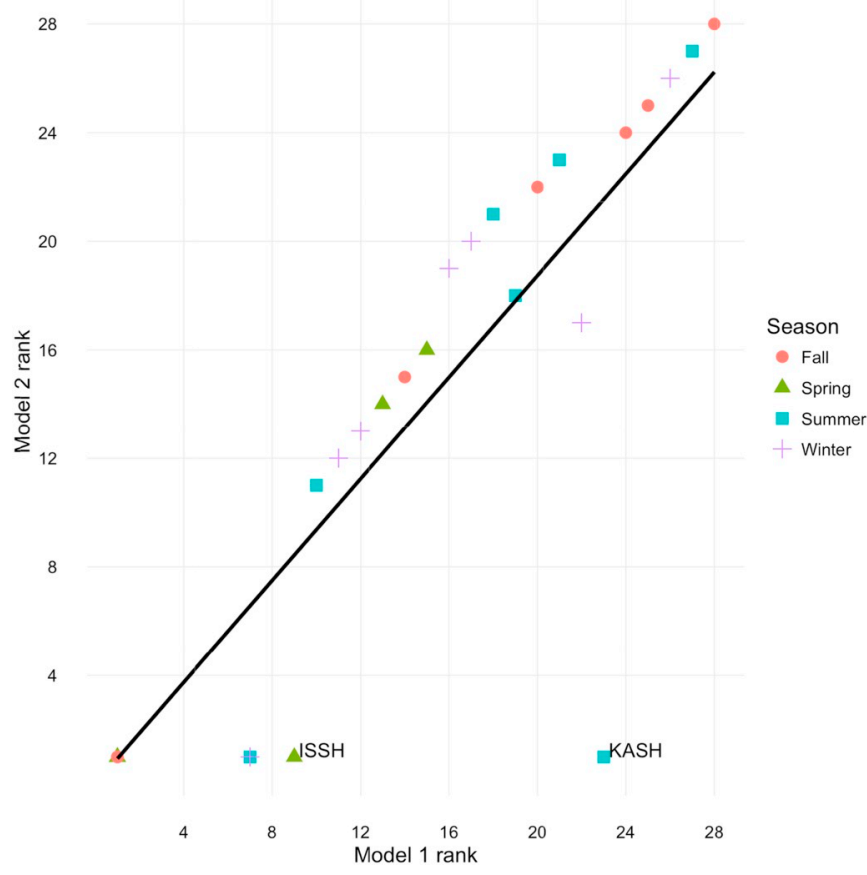

Fig. 7. CAT-I-V 2014 efficiency score rankings.

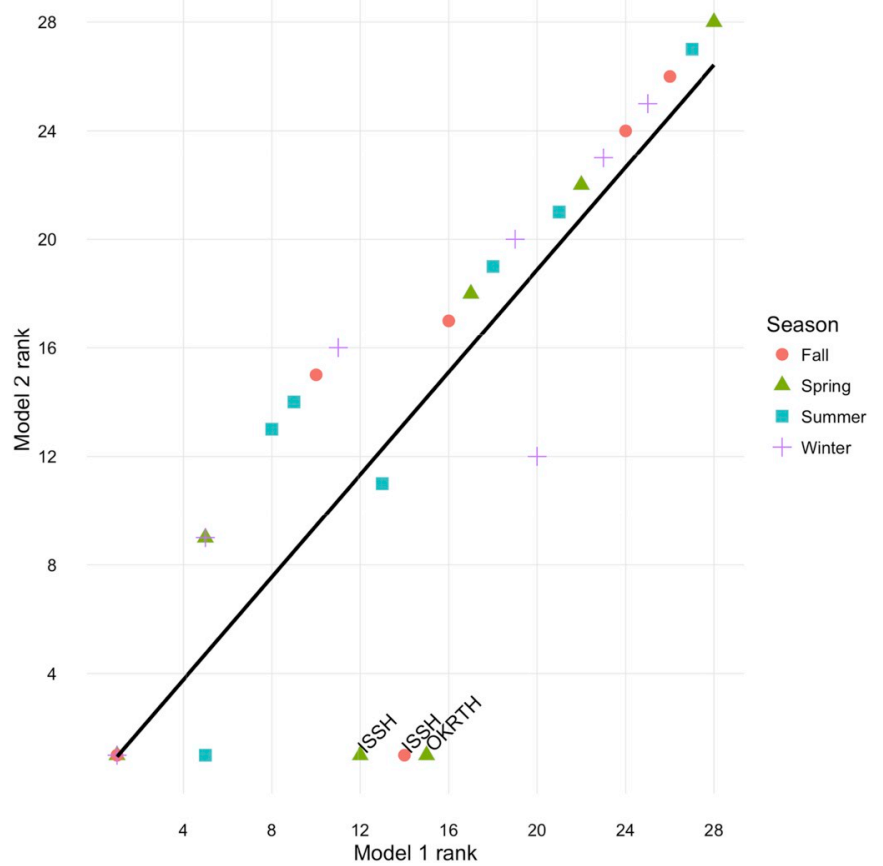

Fig. 8. CAT-I-V 2013 efficiency score rankings.

showed that VRS/CRS distinction was the most significant determinant of the performance differences in the DEA models tested. In fact; VRS models have been suggested by previous studies on hospital efficiency (Dash et al. [42]; Mark et al. [43]; Ozcan et al. [44]; Ketabi [45]; Gautam et al. [46]; Prakash and Annapoorni [47] and our results show that VRS models would be better for EDs as well. On the other hand, to determine whether using only a single output (number of emergency patients) or two outputs (number of emergency patients and number of referrals) made a significant difference in the efficiency rankings of the hospitals, we employed a novel approach utilizing outlier detection with regression.

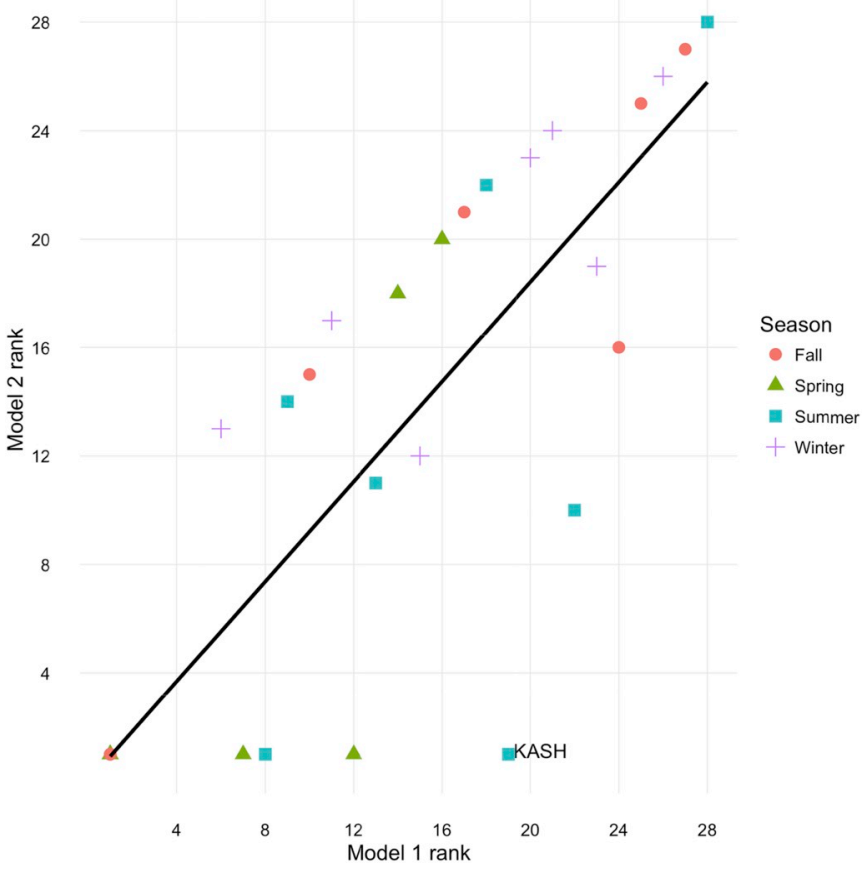

Fig. 9. CAT-O-V 2014 efficiency score rankings.

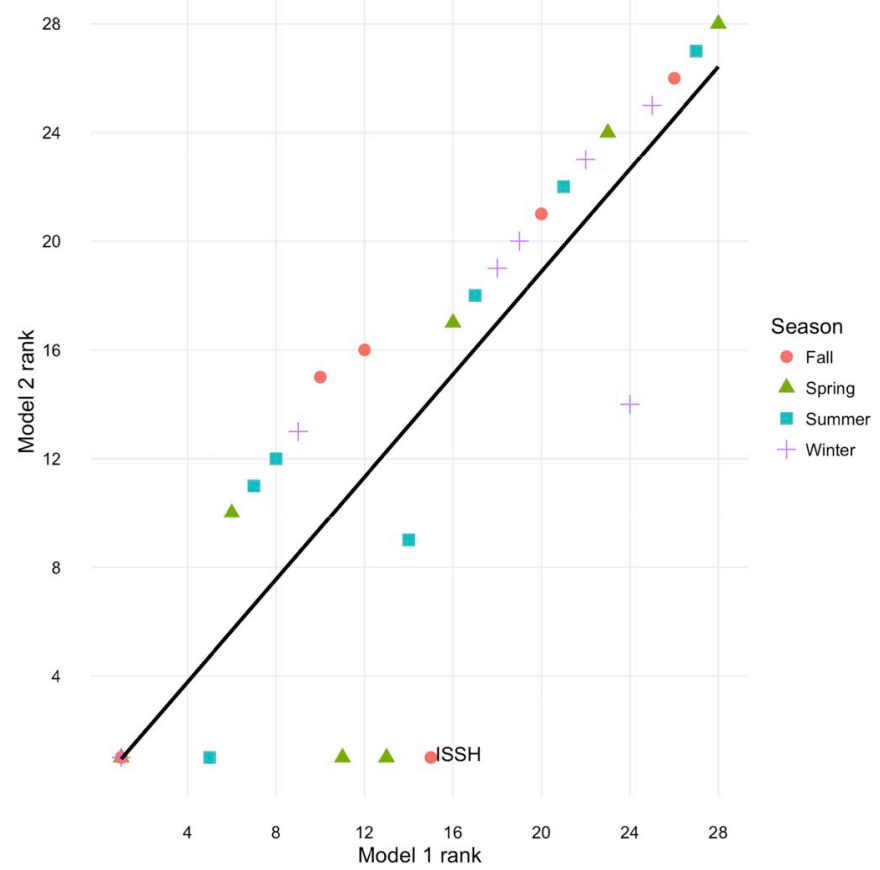

Fig. 10. CAT-O-V 2013 efficiency score rankings.

The results revealed that for two hospitals (KASH and ISSH) including the referral count is necessary to accurately evaluate their efficiencies. Evaluating their efficiency without taking this into account would not be a fair and accurate assessment of their performance. This conclusion provided by our models is validated by the field work which revealed that these hospitals serve a "satellite hospital" mission by referring some of the emergency cases to better-equipped training and research hospitals. We believe, for densely populated cities such as Istanbul, this outcome points to an effective policy of designing EDs in a hub-and-spoke system, where smaller and less-equipped EDs are supported by larger and better-equipped hospitals ("hubs"). In this two- 
tiered emergency care system design, the lower-tiered units that have limited capabilities and capacities would serve a more local population within the city and higher-tier units that have extensive capabilities would serve a wider region, making it a cost-effective approach. If such a system is further supported by an integrated information system, it could prove both highly effective and economically viable.

In terms of the developed methodology, we believe its visual aspect is likely to increase the chance of the hospital administrators to accept the approach and the recommended model. Another advantage of the proposed model is that due to the use of categorical DEA and the level categories of the EDs (which is reliable and trusted by the administrators) reduces the input requirements. Our model can be seen as a proof-of-concept application of categorical DEA models as a practical approach, especially when there is a limited number of DMUs (in this case EDs). Since the categories are defined by the level designations of the MoH which encapsulates many critical characteristics of EDs, the category variable in the DEA models could be effectively used to replace a large number of input variables. We believe these characteristics of the methodology make it easily applicable to the emergency service units of other hospital regions.

The two main policy implications derived from this study can be summarized as follows. Firstly, hospital administrators should consider a hub and spoke system while developing EDs in metropolitan cities (such as Istanbul). Secondly, we suggest hospital administrators to develop if they have not already done so, a level classification system for EDs, which encompass infrastructure and size characteristics of the EDs. Doing so, as shown here, will enable them to carry out efficiency analysis even when there is a small number of EDs under their administration.

The fact that a small number of hospitals has been used in this research, could be seen as one of its main weaknesses. We would like to see researchers testing categorical DEA approaches on other EDs to our conclusions. For the group EDs we have studied there was no data on the case-mix (relative medical complexity of the health services delivered). This could be an important element in modeling the output of EDs and thus another direction of improvement for the models studied here.

\section{Acknowledgments}

This work was supported by TÜBITAK 1001 under Grant 216M026. The authors would like to express their sincere gratitude to the Prof. Erol Kısmet and Asst. Prof. Güven Bektemür from Istanbul's Beyoglu State Hospitals Association, (BSHA), Prof. Cevdet Erdöl from Sağllk Bilimleri University and Dr. Nurgül Osmanbeyoğlu Bektemür from Ümraniye Training and Research Hospital.

\section{Appendix 1-A. Summary of input and output categories}

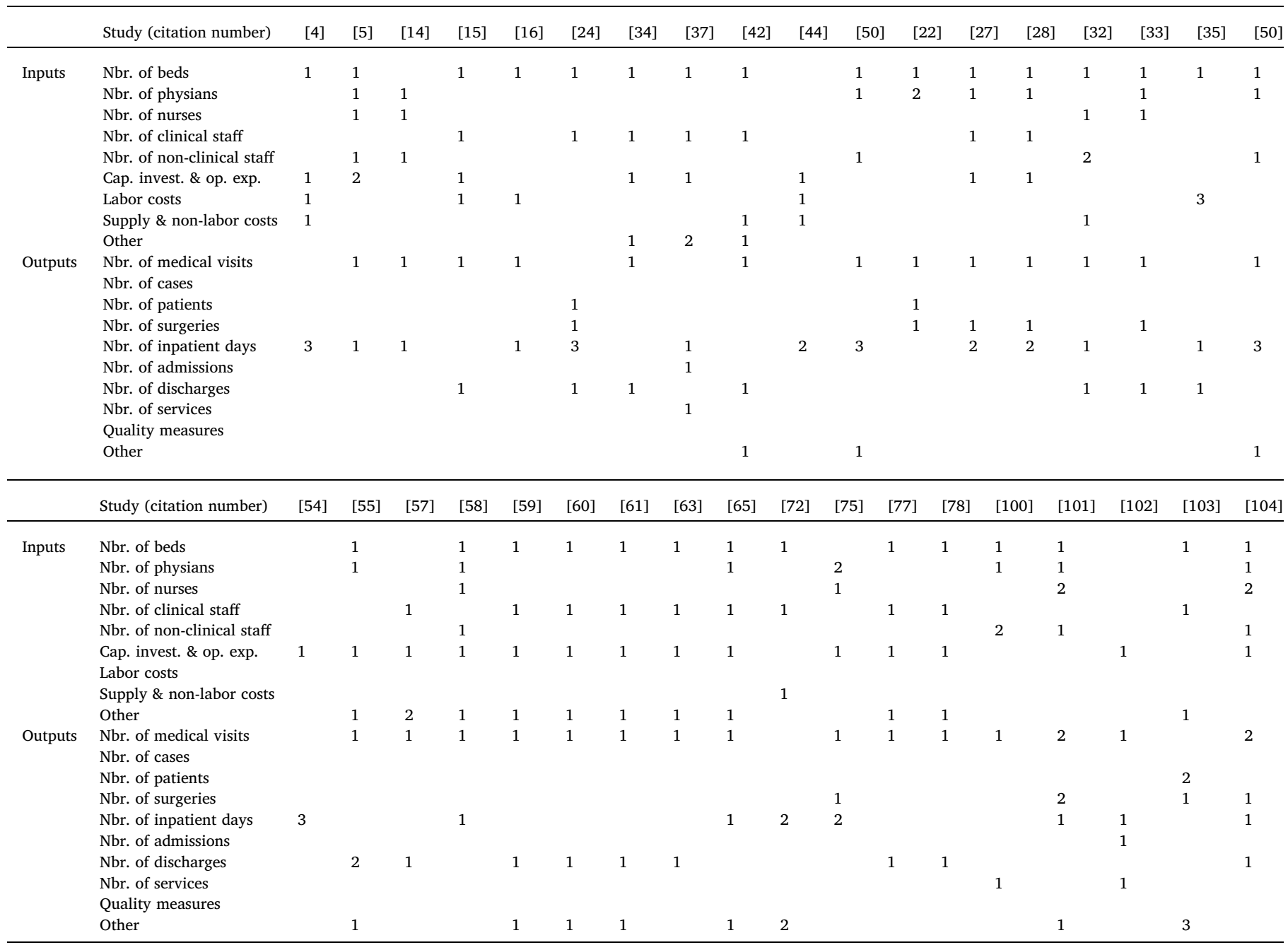




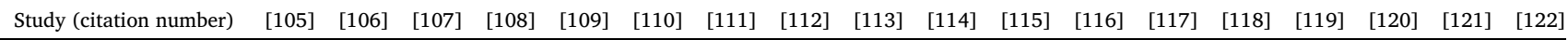

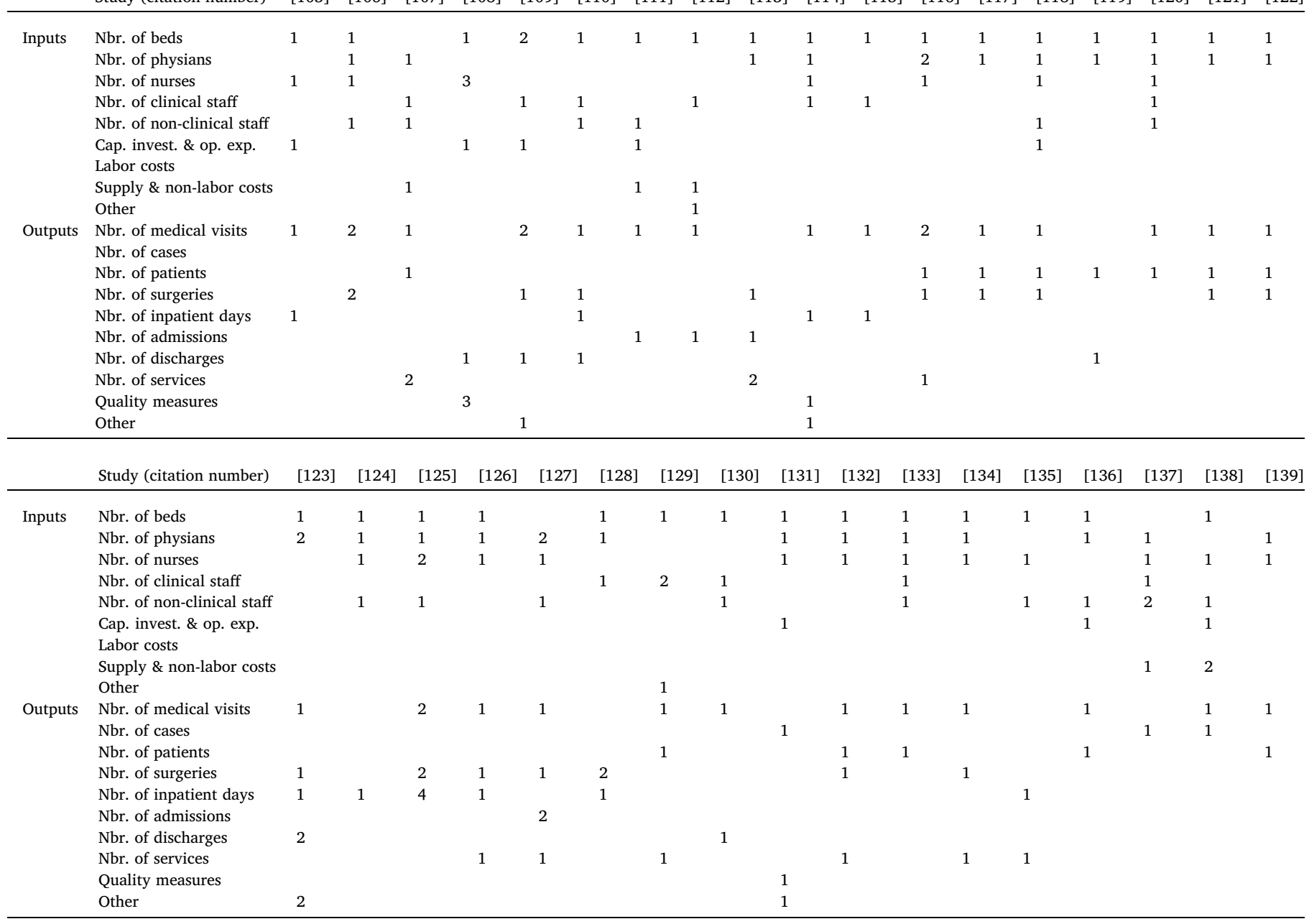

\section{Appendix 1-B. References for Appendix 1-A}

Note: In order to facilitate easier comparison, the numbers next to each reference, up to and including 78 are the numbers the same as those used in Ref. [32].

\begin{tabular}{lll}
\hline$[4][48]$ & {$[101][49]$} & {$[129][50]$} \\
{$[5][51]$} & {$[102][52]$} & {$[130][53]$} \\
{$[14][54]$} & {$[103][55]$} & {$[131][56]$} \\
{$[15][57]$} & {$[104][58]$} & {$[132][59]$} \\
{$[16][60]$} & {$[105][61]$} & {$[133][62]$} \\
{$[22][26]$} & {$[106][63]$} & {$[134][47]$} \\
{$[24][64]$} & {$[107][65]$} & {$[135][66]$} \\
{$[27][67]$} & {$[108][43]$} & {$[136][68]$} \\
{$[28][69]$} & {$[109][70]$} \\
{$[32][72]$} & {$[110][73]$} \\
{$[33][74]$} & {$[111][75]$} \\
{$[34][77]$} & {$[112][78]$} \\
{$[35][79]$} & {$[113][80]$} \\
{$[50][81]$} & {$[114][82]$} \\
{$[54][83]$} & {$[115][84]$} \\
{$[55][85]$} & {$[116][86]$} \\
{$[57][87]$} & {$[117][88]$} \\
{$[58][89]$} & {$[118][29]$} \\
{$[59][90]$} & {$[119][91]$} \\
{$[60][92]$} & {$[120][93]$} \\
{$[61][94]$} & {$[121][95]$} \\
{$[63][96]$} & {$[122][97]$} \\
{$[65][98]$} & {$[123][99]$} \\
{$[72][100]$} & {$[124][101]$} \\
{$[75][102]$} & {$[125][103]$} \\
{$[77][104]$} & {$[126][105]$} \\
{$[78][106]$} & {$[127][17]$} \\
{$[100][107]$} & {$[128][108]$} \\
\hline
\end{tabular}


Appendix 2

A1. DEA Efficiencies for DMU under the 8 DEA Models-2014.

\begin{tabular}{|c|c|c|c|c|c|c|c|c|c|}
\hline No & $\mathrm{DMU}$ & $\mathrm{AB} 1 \mathrm{CI}$ & $\mathrm{AB} 1 \mathrm{CO}$ & $\mathrm{AB} 1 \mathrm{VI}$ & AB1Vo & $\mathrm{AB} 12 \mathrm{CI}$ & $\mathrm{AB} 12 \mathrm{CO}$ & $\mathrm{AB} 12 \mathrm{VI}$ & $\mathrm{AB} 12 \mathrm{VO}$ \\
\hline 1 & ISSH (spring) & 0.437 & 0.437 & 0.939 & 0.964 & 1.000 & 1.000 & 1.000 & 1.000 \\
\hline 2 & EYSH (spring) & 0.392 & 0.392 & 1.000 & 1.000 & 0.447 & 0.447 & 1.000 & 1.000 \\
\hline 3 & GTRH (spring) & 0.374 & 0.374 & 0.891 & 0.927 & 0.456 & 0.456 & 0.896 & 0.930 \\
\hline 4 & KASH (spring) & 0.412 & 0.412 & 0.849 & 0.910 & 0.423 & 0.423 & 0.849 & 0.910 \\
\hline 5 & OKRTH (spring) & 0.327 & 0.327 & 1.000 & 1.000 & 0.327 & 0.327 & 1.000 & 1.000 \\
\hline 6 & SASH (spring) & 0.937 & 0.937 & 1.000 & 0.937 & 1.000 & 1.000 & 1.000 & 1.000 \\
\hline 7 & SERTH (spring) & 1.000 & 1.000 & 1.000 & 1.000 & 1.000 & 1.000 & 1.000 & 1.000 \\
\hline 8 & ISSH (summer) & 0.336 & 0.336 & 0.751 & 0.833 & 0.680 & 0.680 & 0.787 & 0.994 \\
\hline 9 & EYSH (summer) & 0.314 & 0.314 & 0.756 & 0.889 & 0.354 & 0.354 & 0.756 & 0.889 \\
\hline 10 & GTRH (summer) & 0.371 & 0.371 & 0.907 & 0.936 & 0.520 & 0.520 & 0.919 & 0.992 \\
\hline 11 & KASH (summer) & 0.296 & 0.296 & 0.629 & 0.868 & 0.315 & 0.315 & 1.000 & 1.000 \\
\hline 12 & OKRTH (summer) & 0.227 & 0.227 & 0.692 & 0.963 & 0.227 & 0.227 & 0.692 & 0.963 \\
\hline 13 & SASH (summer) & 0.964 & 0.964 & 1.000 & 0.964 & 1.000 & 1.000 & 1.000 & 1.000 \\
\hline 14 & SERTH (summer) & 0.169 & 0.169 & 0.176 & 0.376 & 0.169 & 0.169 & 0.176 & 0.376 \\
\hline 15 & ISSH (fall) & 0.240 & 0.240 & 0.527 & 0.764 & 0.463 & 0.463 & 0.550 & 0.947 \\
\hline 16 & EYSH (fall) & 0.302 & 0.302 & 0.732 & 0.899 & 0.334 & 0.334 & 0.732 & 0.899 \\
\hline 17 & GTRH (fall) & 0.348 & 0.348 & 0.870 & 0.960 & 0.348 & 0.348 & 0.870 & 0.960 \\
\hline 18 & KASH (fall) & 0.341 & 0.341 & 1.000 & 1.000 & 0.353 & 0.353 & 1.000 & 1.000 \\
\hline 19 & OKRTH (fall) & 0.142 & 0.142 & 0.417 & 0.658 & 0.142 & 0.142 & 0.417 & 0.671 \\
\hline 20 & SASH (fall) & 1.000 & 1.000 & 1.000 & 1.000 & 1.000 & 1.000 & 1.000 & 1.000 \\
\hline 21 & SERTH (fall) & 0.110 & 0.110 & 0.112 & 0.385 & 0.110 & 0.110 & 0.112 & 0.403 \\
\hline 22 & ISSH (winter) & 0.348 & 0.348 & 0.686 & 0.803 & 0.812 & 0.812 & 0.827 & 0.914 \\
\hline 23 & EYSH (winter) & 0.360 & 0.360 & 0.904 & 0.968 & 0.399 & 0.399 & 0.904 & 0.968 \\
\hline 24 & GTRH (winter) & 0.338 & 0.338 & 0.786 & 0.853 & 0.360 & 0.360 & 0.786 & 0.853 \\
\hline 25 & KASH (winter) & 0.428 & 0.428 & 0.906 & 0.944 & 0.432 & 0.432 & 0.906 & 0.944 \\
\hline 26 & OKRTH (winter) & 0.253 & 0.253 & 0.764 & 0.860 & 0.253 & 0.253 & 0.764 & 0.865 \\
\hline 27 & SASH (winter) & 0.924 & 0.924 & 1.000 & 0.924 & 0.977 & 0.977 & 1.000 & 0.977 \\
\hline 28 & SERTH (winter) & 0.199 & 0.199 & 0.206 & 0.436 & 0.218 & 0.218 & 0.223 & 0.515 \\
\hline
\end{tabular}

\section{References}

[1] OECD. Health at a Glance 2017: OECD Indicators. Paris: OECD Publishing; 2017https://doi.org/10.1787/health_glance-2017-en.

[2] TOBB. A General Look at Turkey's Health Sector (in Turkish) (Sağlık Kurumları Meclisi: Türk Sağlık Sektörüne. 2017.

[3] World Bank. Tracking universal health coverage: 2017 global monitoring report (English). Washington, D.C.: World Bank Group; 2017.

[4] Berchet C. Emergency Care Services: Trends, Drivers and Interventions to Manage the Demand. Paris: OECD Publishing; 2015. OECD Health Working Papers, No. 83 https://doi.org/10.1787/5jrts344crns-en.

[5] World Bank. GDP rankings. 2017. Retrieved March 1, 2018, from https:// datacatalog.worldbank.org/dataset/gdp-ranking.

[6] Buğra A, Yılmaz V, Birelma A, Gürsoy B, Taşkın Y, Dodurka ZB, Akkan BE, Göçmen İ. Inequalities in Turkey: An Overview. UNDP Regional Human Development; 2016.

[7] Torul O, Öztunalı O. On income and wealth inequality in Turkey. Central Bank Review; 2018.

[8] Akdag R. Turkey Health Transformation Program - Evaluation Report. 2011. p. 2003-10.

[9] Bektemür G, Osmanbeyoğlu N, Cander B. Acil Hizmetler Raporu. Eurasian J Emerg Med 2015;14. Retrieved from http://www.eajem.com/sayilar/244/buyuk/ EAJEM-Ozel-Sayi.pdf.

[10] Hürriyet. Acilleri "acil" olmayanlar meşgul ediyor... Trabzon'da acile günde 3 binden fazla kişi gidiyor. 2018. Retrieved March 1, 2018, from http://www. hurriyet.com.tr/acilleri-acil-olmayanlar-mesgul-ediyor-trabzonda-acile-gunde-3binden-fazla-kisi-gidiyor-40724663.

[11] Hollingsworth B. The measurement of efficiency and productivity of health care delivery. Health Econ 2008;17:1107-28https://doi.org/10.1002/hec.

[12] Charnes A, Cooper WW, Rhodes E. Measuring the efficiency of decision making units. Eur J Oper Res 1978;2(6):429-44https://doi.org/10.1016/0377-2217(78) 90138-8.

[13] Banker RD, Charnes A, Cooper WW. Some models for estimating technical and scale inefficiencies in data envelopment analysis. Manag Sci 1984;30(9):1078-92.

[14] Sahin I, Ozcan YA. Public sector hospital efficiency for provincial markets in Turkey. J Med Syst 2000;24(6):307-20https://doi.org/10.1023/ A:1005576009257.

[15] Campos MS, Fern-andez-Montez A, Gavilan JM, Velasco F. Public resource usage in health systems: a data envelopment analysis of the efficiency of health systems of autonomous communities in Spain. Publ Health 2016;138:33-40.
[16] Hadad S, Hadad Y, Simon-Tuval. Determinants of healthcare system's efficiency in OECD countries. Eur J Health Econ 2013;14:253https://doi.org/10.1007/s10198011-0366-3.

[17] Mitropoulos P, Mitropoulos I, Sissouras A. Managing for efficiency in health care: The case of Greek public hospitals. Eur J Health Econ 2013;14(6):929-38https:// doi.org/10.1007/s10198-012-0437-0.

[18] Oikonomou N, Tountas Y, Mariolis A, Souliotis K. Measuring the efficiency of the Greek rural primary health care using a restricted DEA model; the case of southern and western Greece. Health Care Manag Sci 2016;19:313-25.

[19] Chowdhury H, Zelenyuk V. Performance of hospital services in Ontario: DEA with truncated regression approach. Omega 2016;63:111-22https://doi.org/10.1016/j. omega.2015.10.007.

[20] Mousa W, Aldehayyat JS. Regional efficiency of healthcare services in Saudi Arabia. Middle East Dev J 2018;10(1):152-74. https://doi.org/10.1080/ 17938120.2018.1443607.

[21] Kang H, Nembhard H, DeFlitch C, Pasupathy K. Assessment of emergency department efficiency using data envelopment analysis. IISE Trans Healthc Systems Eng 2017;7(4):236-46.

[22] Kellerman AL. Crisis in the Emergency Department. N Engl J Med 2006;355:1300-3.

[23] Cordero JM, Alonso-Morán E, Nuño-Solinis R, Orueta JF, Arce RS. Efficiency assessment of primary care providers: A conditional nonparametric approach. Eur J Oper Res 2015;240(1):235-44https://doi.org/10.1016/j.ejor.2014.06.040.

[24] Helton JR, Langabeer JR. Longitudinal changes in the operating efficiency of public safety-net hospitals. J Healthc Manag 2012;57(3):214-26.

[25] Cakmak M, Öktem MK, Ömürgönülsen U. The Efficiency Problem of Turkish Public Hospitals: The Measurement of Technical Efficiency of Maternity Hospitals by Data Envelopment Analysis. Hacet J Health Adm 2009;12(1):1-36.

[26] Ersoy K, Kavuncubasi S, Ozcan YA, Harris JM. Technical efficiencies of Turkish hospitals: DEA approach. J Med Syst 1997;21(2):67-74https://doi.org/10.1023/ A:1022801222540.

[27] Temür Y, Bakırcı F. An analysis of the health organization in Turkey: A DEA application. Sos Bilimler Derg 2008;10(3):261-81.

[28] Bayraktutan Y, Arslan I, Bal V. The evaluation of the effects of health information systems to the performance of hospitals by data enveloping analysis: An application in the thoracic medicine hospitals. Gaziantep Med J 2010;16(3):13-8.

[29] Sahin I, Ozcan YA, Ozgen H. Assessment of hospital efficiency under health transformation program in Turkey. Cent Eur J Oper Res 2011;19:19-37https:// doi.org/10.1007/s10100-009-0121-3.

[30] Ozgen H, Sahin I. Measurement of efficiency of the dialysis sector in Turkey using data envelopment analysis. Health Policy 2010;95(2-3):185-93https://doi.org/ 
10.1016/j.healthpol.2009.11.020.

[31] Bilsel M, Davutyan N. Hospital efficiency with risk adjusted mortality as undesirable output: the Turkish case. Ann Oper Res 2014;221(1):73-88https://doi. org/10.1007/s10479-011-0951-y.

[32] O'Neill L, Rauner M, Heidenberger K, Kraus M. A cross-national comparison and taxonomy of DEA-based hospital efficiency studies. Soc Econ Plann Sci 2008;42(3):158-89https://doi.org/10.1016/j.seps.2007.03.001.

[33] Offical Gazette of Turkish Republic, No: 27378, 2009.

[34] Banker RD, Morey RC. Efficiency analysis for exogenously fixed inputs and outputs. Oper Res 1986;34(4):513-21https://doi.org/10.1287/opre.34.4.513.

[35] Tasköprü V. Comparative Analysis of classical data envelopment analysis and categorical data envelopment analysis models for energy efficiency. Mimar Sinan Fine Arts University; 2014.

[36] Golany B, Roll Y. An application procedure for DEA. Omega 1989;17(3):237-50.

[37] Cooper WW, Seiford LM, Tone K. Data Envelopment Analysis: A Comprehensive Text with Models, Applications, References and DEA-Solver Software. second ed. Boston, MA: Springer Science + Business Media, LLC; 2007.

[38] Cinca CS, Molinero CM. Selecting DEA specifications and ranking units via PCA. J Oper Res Soc 2004;55(5):521-8.

[39] Sagarra M, Mar-Molinero C, Agasisti T. Exploring the efficiency of Mexican universities: Integrating Data Envelopment Analysis and Multidimensional Scaling. Omega (United Kingdom) 2017;67:123-33https://doi.org/10.1016/j.omega. 2016.04.006.

[40] Schiffman SS, Reynolds ML, Young FW. Introduction to multidimensional scaling: Theory, methods and applications. London: Academic Press Inc; 1981.

[41] Hair JF, Black JW, Babib BJ, Anderson RE. Multivariate Data Analysis. seventh ed. Pearson; 2014.

[42] Dash U, Vaishnavi SD, Muraleedharan VR, Acharya D. Benchmarking the performance of public hospitals in Tamil Nadu: An application of data envelopment analysis. J Health Manag 2007;9:59-74.

[43] Mark BA, Jones CB, Lindley L, Ozcan YA. An examination of technical efficiency, quality, and patient safety in acute care nursing units. Pol Polit Nurs Pract 2009;10(3):180-6https://doi.org/10.1177/1527154409346322.

[44] Ozcan YA, Lins ME, Stella M, Lobo C, Da Silva ACM, Fiszman R, Pereira BB. Evaluating the performance of Brazilian university hospitals. Ann Oper Res 2010;178:247-61.

[45] Ketabi S. Efficiency measurement of cardiac care units of Isfahan hospitals in Iran. J Med Syst 2011;35:143-50.

[46] Gautam S, Hicks L, Johnson T, Mishra B. Measuring the performance of critical access hospitals in Missouri using data envelopment analysis. J Rural Health 2013:29:150-8.

[47] Prakash V, Annapoorni D. Performance Evaluation of Public Hospitals in Tamil Nadu: DEA Approach. J Health Manag 2015;17(4):417-24https://doi.org/10. $1177 / 0972063415606267$.

[48] Banker RD, Conrad RF, Strauss RP. A comparative application of data envelopment analysis and translog methods: an illustrative study of hospital production. Manag Sci 1986;32(1):30-44.

[49] Ferrier GD, Rosko MD, Valdmanis VG. Analysis of uncompensated hospital care using a DEA model of output congestion. Health Care Manag Sci 2006;9(2):181-8https://doi.org/10.1007/s10729-006-7665-8.

[50] Audibert M, Mathonnat J, Pelissier A, Huang XX, Ma A. Health insurance reform and efficiency of township hospitals in rural China: An analysis from survey data. China Econ Rev 2013;27:326-38https://doi.org/10.1016/j.chieco.2013.01.004.

[51] Bannick RR, Ozcan YA. Efficiency analysis of federally funded hospitals: Comparison of DoD and VA hospitals using data envelopment analysis. Health Serv Manag Res 1995;8(2):73-85https://doi.org/10.1177/095148489500800201.

[52] Linna M, Häkkinen U, Magnussen J. Comparing hospital cost efficiency between Norway and Finland. Health Policy 2006;77(3):268-78https://doi.org/10.1016/j. healthpol.2005.07.019.

[53] Leleu H, Moises J, Valdmanis VG. How do payer mix and technical inefficiency affect hospital profit? A weighted DEA approach. Oper Res Health Care 2014;3(4):231-7https://doi.org/10.1016/j.orhc.2014.06.002.

[54] Chang H. Determinants of Hospital Efficiency: the Case of Central Governmentowned Hospitals in Taiwan. Omega 1998;26(2):307-17https://doi.org/10.1016/ S0305-0483(98)00014-0.

[55] Wang R, Yu M. Evaluating the Efficiency of Hospital's Departments Using DEA. IEEE International Conference on Service Operations and Logistics, and Informatics. 2006. p. 1167-70. Shanghai https://doi.org/10.1109/SOLI.2006. 328916.

[56] Du J, Wang J, Chen Y, Chou S-Y, Zhu J. Incorporating health outcomes in Pennsylvania hospital efficiency: an additive super-efficiency DEA approach. Ann Oper Res 2014;221(1):161-72https://doi.org/10.1007/s10479-011-0838-y.

[57] Chern JY, Wan TTH. The impact of the prospective payment system on the tech nical efficiency of hospitals. J Med Syst 2000;24(3):159-72https://doi.org/10. 1023/A:1005542324990.

[58] Bates LJ, Mukherjee K, Santerre RE. Market structure and technical efficiency in the hospital services industry: A DEA approach. Med Care Res Rev 2006;63(4):499-524https://doi.org/10.1177/1077558706288842.

[59] Applanaidu SD, Samsudin S, Ali J, Dash U, Chik AR. Technical and Scale Efficiency of Public District Hospitals in Kedah, Malaysia: A Data Envelopment Analysis (DEA). J Health Manag 2014;16(3):327-35https://doi.org/10.1177/ 0972063414539595.

[60] Chirikos TN, Sear AM. Technical efficiency and the competitive behavior of hospitals. Soc Econ Plann Sci 1994;28(4):219-27https://doi.org/10.1016/00380121(94)90027-2.

[61] Zere E, Mbeeli T, Shangula K, Mandlhate C, Mutirua K, Tjivambi B, Kapenambili
W. Technical efficiency of district hospitals: Evidence from Namibia using data envelopment analysis. Cost Eff Resour Allocation 2006;4:1-9https://doi.org/10. 1186/1478-7547-4-5.

[62] Yang J, Zeng W. The trade-offs between efficiency and quality in the hospital production: some evidence from Shenzhen, China. China Econ Rev 2014;31:166-84https://doi.org/10.1016/j.chieco.2014.09.005.

[63] Hajialiafzali H, Moss JR, Mahmood M a. Efficiency measurement for hospitals owned by the Iranian social security organisation. J Med Syst 2007;31(3):166-72https://doi.org/10.1007/s10916-007-9051-6.

[64] Ferrier G, Valdmanis V. Rural hospital performance and its correlates. J Prod Anal 1996;80:63-80.

[65] Masiye F. Investigating health system performance: An application of data envelopment analysis to Zambian hospitals. BMC Health Serv Res 2007;7:1-11https://doi.org/10.1186/1472-6963-7-58.

[66] Karagiannis R. A system-of-equations two-stage DEA approach for explaining capacity utilization and technical efficiency. Ann Oper Res 2015;227(1):25-43https://doi.org/10.1007/s10479-013-1367-7.

[67] Grosskopf S, Valdmanis VG. Measuring hospital performance. A non-parametric approach. J Health Econ 1987;6:89-107https://doi.org/10.1016/0167-6296(87) 90001-4.

[68] Mitropoulos P, Talias MA, Mitropoulos I. Combining stochastic DEA with Bayesian analysis to obtain statistical properties of the efficiency scores: An application to Greek public hospitals. Eur J Oper Res 2015;243(1):302-11https://doi.org/10. 1016/j.ejor.2014.11.012.

[69] Grosskopf S, Valdmanis V. Evaluating hospital performance with case-mix-adjusted outputs. Med Care 1993;31(6):525-32.

[70] Zhong J. Comparative study on performance assessment of hospitals in various regions of China through comprehensive variable DEA and traditional DEA. Proceedings - 2009 2nd IEEE International Conference on Computer Science and Information Technology, ICCSIT 2009. 2009. p. 423-7https://doi.org/10.1109/ ICCSIT.2009.5235015.

[71] Lindlbauer I, Schreyögg J, Winter V. Changes in technical efficiency after quality management certification: A DEA approach using difference-in-difference estimation with genetic matching in the hospital industry. Eur J Oper Res 2016;250(3):1026-36https://doi.org/10.1016/j.ejor.2015.10.029.

[72] Gruca TS, Nath D. The technical efficiency of hospitals under a single payer system: the case of Ontario community hospitals. Health Care Manag Sci 2001;4(2):91-101https://doi.org/10.1023/A:1011401510010.

[73] Sengupta A, Mondal SK. Efficiency and financing in catering primary health care to the poors: A study of rural health services in India. J Health Manag 2009;11(3):501-26https://doi.org/10.1177/097206340901100304.

[74] Hao SHS, Pegels CC. Evaluating relative efficiencies of Veterans Affairs medical centers using data envelopment, ratio, and multiple regression analysis. J Med Syst 1994;18(2):55-67https://doi.org/10.1007/BF00999452.

[75] Kazley AS, Ozcan YA. Electronic medical record use and efficiency: A DEA and windows analysis of hospitals. Soc Econ Plann Sci 2009;43(3):209-16https://doi. org/10.1016/j.seps.2008.10.001.

[76] Toloo M, Jalili R. LU Decomposition in DEA with an Application to Hospitals. Comput Econ 2016;47(3):473-88https://doi.org/10.1007/s10614-015-9501-z.

[77] Harris J, Ozgen H, Ozcan Y. Do mergers enhance the performance of hospital efficiency? J Oper Res Soc 2000;51(7):801-11https://doi.org/10.1057/palgrave. jors. 2600869.

[78] Sikka V, Luke RD, Ozcan YA. The efficiency of hospital-based clusters: Evaluating system performance using data envelopment analysis. Health Care Manag Rev 2009;34(3):251-61https://doi.org/10.1097/HMR.0b013e3181a16ba7.

[79] Hofmarcher MM, Paterson I, Riedel M. Measuring hospital efficiency in Austria-a DEA approach. Health Care Manag Sci 2002;5(1):7-14https://doi.org/10.1023/ A:1013292801100.

[80] Caballer-Tarazona M, Moya-Clemente I, Vivas-Consuelo D, Barrachina-Martínez I A model to measure the efficiency of hospital performance. Math Comput Model 2010;52(7-8):1095-102https://doi.org/10.1016/j.mcm.2010.03.006.

[81] Mobley LR, Magnussen J. An international comparison of hospital efficiency: does institutional environment matter? Appl Econ 1998;30:1089-100https://doi.org/ 10.1023/A:1005542324990.

[82] Chuang C-L, Chang P-C, Lin R-H. An Efficiency Data Envelopment Analysis Model Reinforced by Classification and Regression Tree for Hospital Performance Evaluation. J Med Syst 2011;35(5):1075-83https://doi.org/10.1007/s10916-0109598-5.

[83] Nunamaker T. Measuring routine nursing service efficiency: a comparison of cost per patient day and data envelopment analysis models. Health Serv Res 1983;18(2):183-205.

[84] Tlotlego N, Nonvignon J, Sambo LG, Asbu EZ, Kirigia JM. Assessment of productivity of hospitals in Botswana: A DEA application. Int Arch Med 2010;3(1):27https://doi.org/10.1186/1755-7682-3-27.

[85] O'Neill L. Multifactor efficiency in data envelopment analysis with an application to urban hospitals. Health Care Manag Sci 1998;1:19-27.

[86] Dash U, Vaishnavi SD, Muraleedharan VR. Technical efficiency and scale efficiency of district hospitals: A case study. J Health Manag 2010;12(3):231-48https://doi. org $/ 10.1177 / 097206341001200302$.

[87] Ozcan YA. Efficiency of Hospital-Service Production in Local Markets - the Balance-Sheet of Us Medical Armament. Soc Econ Plann Sci 1995;29(2):139-50https://doi.org/10.1016/0038-0121(95)00006-8.

[88] Wei CK, Chen LC, Li RK, Tsai CH. Exploration of efficiency underestimation of CCR model: Based on medical sectors with DEA-R model. Expert Syst Appl 2011;38(4):3155-60https://doi.org/10.1016/j.eswa.2010.08.108.

[89] Ozcan YA, Bannick RR. Trends in Department of Defence hospital efficiency. J Med 
Syst 1994;18(2):69-83.

[90] Ozcan YA, Luke R. A national study of the efficiency of hospitals in urban markets. Health Serv Res 1993;27(6):719-39.

[91] Androutsou L, Geitona M, Yfantopoulos J. Measuring efficiency and productivity across hospitals in the regional health authority of Thessaly, in Greece. J Health Manag 2011;13(2):121-40https://doi.org/10.1177/097206341101300201.

[92] Ozcan YA, Luke RD, Haksever C. Ownership and Organizational Performance - A Comparison of Technical Efficiency Across Hospital Types. Med Care 1992;30(9):781-94.

[93] Ng YC. The productive efficiency of Chinese hospitals. China Econ Rev 2011;22(3):428-39https://doi.org/10.1016/j.chieco.2011.06.001.

[94] Ozcan YA, Lynch JR. Rural hospital closures: an inquiry into efficiency. Adv Health Econ Health Serv Res 1992;13:205-24.

[95] Wei CK, Chen LC, Li RK, Tsai CH. Using the DEA-R model in the hospital industry to study the pseudo-inefficiency problem. Expert Syst Appl 2011;38(3):2172-6https://doi.org/10.1016/j.eswa.2010.08.003.

[96] Ozcan YA, McCue MJ, Okasha AA. Measuring the technical efficiency of psychiatric hospitals. J Med Syst 1996;20(3):141-50https://doi.org/10.1007/ BF02281992.

[97] Wei CK, Chen LC, Li RK, Tsai CH, Huang HL. A study of optimal weights of Data Envelopment Analysis - Development of a context-dependent DEA-R model. Expert Syst Appl 2012;39(4):4599-608https://doi.org/10.1016/j.eswa.2011.10.001.

[98] Perez ED. Regional variation in VAMC's operative efficiency. J Med Syst 1992;16(5):207-13https://doi.org/10.1007/BF01000273.

[99] Gok SM, Sezen B. Capacity inefficiencies of teaching and non- teaching hospitals. Serv Ind J 2012;32(14):2307-28https://doi.org/10.1080/02642069.2011. 582495.

[100] Sherman HD. Hospital efficiency measurement and evaluation empirical test of a new technique. Med Care 1984;22(10):922-38.

[101] Karagiannis R, Velentzas K. Productivity and quality changes in Greek public hospitals. Oper Res 2012;12(1):69-81https://doi.org/10.1007/s12351-0100080-4.

[102] Valdmanis VG. Ownership and Technical Efficiency of Hospitals. Med Care 1990;28(6):552-61.

[103] Ferrier GD, Trivitt JS. Incorporating quality into the measurement of hospital efficiency: a double DEA approach. J Prod Anal 2013;40(3):337-55https://doi.org/ 10.1007/s11123-012-0305-z.

[104] Wang BB, Ozcan YA, Wan TTH, Harrison J. Trends in hospital efficiency among metropolitan markets. J Med Syst 1999;23(2):83-97https://doi.org/10.1023/ A:1020585118381.

[105] Kounetas K, Papathanassopoulos F. How efficient are Greek hospitals? A case study using a double bootstrap DEA approach. Eur J Health Econ 2013;14(6):979-94https://doi.org/10.1007/s10198-012-0446-z.

[106] White KR, Ozcan YA. Church ownership and hospital efficiency. Hosp Health Serv
Adm 1996;41(3):297-310.

[107] Osei D, d'Almeida S, George MO, Kirigia JM, Mensah AO, Kainyu LH. Technical efficiency of public district hospitals and health centres in Ghana: A pilot study. Cost Eff Resour Allocation 2005;3:1-13https://doi.org/10.1186/1478-7547-3-9.

[108] Ajlouni MM, Zyoud A, Jaber B, Shaheen H, Al-natour M, Anshasi RJ. Assessing the relative efficiency of Jordanian public hospitals using data envelopment analysis and Pabon Lasso. Glob J Bus Res 2013;7(2):36-49.

[109] Hafidz F, Ensor T, Tubeuf S. Efficiency measurement in health facilities: A systematic review in low- and middle-income countries. Appl Health Econ Health Policy 2018;16:465-80. https://doi.org/10.1007/s40258-018-0385-7.

Can Akkan is an Professor of Operations Management and Business Analytics in the School of Management at Sabancı University, Istanbul. His work is mainly on applied mathematical programming and design of heuristic algorithms in manufacturing, project management and service operations, focusing mostly on planning and scheduling models.

Melis Almula Karadayi is an Assistant Professor in the Industrial Engineering Department at Istanbul Medipol University. Her areas of interest include healthcare management, waste management, multiple criteria decision making, data envelopment analysis, fuzzy optimization, and applications of mathematical programming and fuzzy set theory.

Yeliz Ekinci is an Assistant Professor in the Department of Business Administration at Istanbul Bilgi University. Her work focuses on decision making, statistics, and operations research topics. Her refereed articles have appeared in a variety of journals and in the proceedings of major national and international conferences.

Füsun Ülengin is a Professor of Operations Research and Decision Analysis in the School of Management at Sabanc1 University, Istanbul. Her research focuses on the multi-objective evaluation of macrosystems in general, and transportation and logistics systems, in particular. Dr. Ülengin has also interests in multi-attribute and group decision-making models, decision support systems, Bayesian causal maps and neural networks.

Nimet Uray is a Professor of Marketing in the Department of Business Administration at Kadir Has University, Istanbul. Her research focuses on Customer Behavior and Customer Relationship Management, Marketing Communications, Marketing-Operations \& Technology Interface.

Elif Karaosmanoğlu is an Associate Professor of Marketing in the Department of Management Engineering at Istanbul Technical University. Her research streams mainly focus on Corporate Marketing and Branding and Consumer-Technology Interactions. 